Hydrol. Earth Syst. Sci. Discuss., 5, 95-145, 2008

www.hydrol-earth-syst-sci-discuss.net/5/95/2008/

(C) Author(s) 2008. This work is licensed

under a Creative Commons License.

\title{
Inverse modeling of soil characteristics from surface soil moisture observations: potential and limitations
}

\section{A. Loew and W. Mauser}

University of Munich, Department of Geography, Munich, Germany

Received: 28 November 2007 - Accepted: 8 December 2007 - Published: 23 January 2008

Correspondence to: A. Loew (a.loew@Imu.de)

Soil parameter inversion - potential and limits

\section{A. Loew and W. Mauser}

Title Page

Abstract

Conclusions

Tables

14

4

Back
Introduction

References

Figures

I

$>$

Close

Full Screen / Esc

Printer-friendly Version

Interactive Discussion 


\section{Abstract}

Land surface models (LSM) are widely used as scientific and operational tools to simulate mass and energy fluxes within the soil vegetation atmosphere continuum for numerous applications in meteorology, hydrology or for geobiochemistry studies. A re-

5 liable parameterization of these models is important to improve the simulation skills. Soil moisture is a key variable, linking the water and energy fluxes at the land surface. An appropriate parameterisation of soil hydraulic properties is crucial to obtain reliable simulation of soil water content from a LSM scheme. Parameter inversion techniques have been developed for that purpose to infer model parameters from soil moisture measurements at the local scale. On the other hand, remote sensing methods provide a unique opportunity to estimate surface soil moisture content at different spatial scales and with different temporal frequencies and accuracies. The present paper investigates the potential to use surface soil moisture information to infer soil hydraulic characteristics using uncertain observations. Different approaches to retrieve soil characteristics 15 from surface soil moisture observations is evaluated and the impact on the accuracy of the model predictions is quantified. The results indicate that there is in general potential to improve land surface model parameterisations by assimilating surface soil moisture observations. However, a high accuracy in surface soil moisture estimates is required to obtain reliable estimates of soil characteristics.

\section{Introduction}

Soil moisture is a key link between the land surface and the atmosphere as it is an important parameter for many energy-balance related modeling applications such as numerical weather forecasting, climate prediction, radiative transfer modeling, global change modeling and other land process models (Owe et al., 2008). Land surface models have become indispensable tools to quantify and integrate the most important physical, chemical and biological processes in the unsaturated zone of soils. However,
HESSD

5, 95-145, 2008

\section{Soil parameter} inversion - potential and limits

A. Loew and W. Mauser

Title Page

Abstract

Introduction

Conclusions

Tables

References

Figures

14

$\rightarrow 1$

4

Back

Close

Full Screen / Esc

Printer-friendly Version

Interactive Discussion 
the use of these models requires model parameters to describe soil and vegetation properties. At the same time these data are usually fragmented, are of different accuracy and might change in time and space. Especially the temporal and spatial variability of soil hydraulic parameters (e.g. soil porosity, saturated conductivity) might have 5 considerable effect on LSM simulations. Despite the progress that has been made in direct measurement of hydraulic characteristics of soils, these techniques remain relatively time consuming and therefore costly. However, direct or indirect observations of soil moisture dynamics might be used to infer soil hydraulic characteristics.

Various model calibration procedures have been developed that adjust model pa10 rameter values to represent as closely as possible observations of a real system (Vrugt et al., 2003). In order to automatically calibrate model parameters, algorithms defining maximum likelihood functions for the measurement of the closeness between the model results and observations are defined and the model parameters are then optimised. A variety of global or local optimisation methods, such as the Shuffeld Complex 15 Evolution (SCE) algorithm (e.g. Duan et al., 1992; Yapo et al., 1998) or simulated annealing (Thyer et al., 1999) have been used. Several studies have made an intercomparison of these different approaches (Madsen et al., 2002; Thyer et al., 1999).

While in situ measurements are restricted to small areas, remote sensing techniques are able to cover larger areas, which might offer the opportunity to infer soil characteristics from these observation time series (Santanello et al., 2007). Numerous attempts have been made to optimise LSM soil parameters using observations of soil water content and/or soil temperature (e.g. Gupta et al., 1999; Hogue et al., 2005; Liu et al., 2005).

Inverse modeling of soil hydraulic parameters is an established method to optimise 25 the parameterization of land surface models (Vrugt et al., 2003, 2005; Mertens et al., 2006). Soil parameters might be inferred from observations to reproduce LSM simulations that best coincident with observed soil moisture or soil temperature dynamics. Nevertheless, the inverse modeling of soil characteristics does not necessarily result in physically meaningful, thus realistic, model parameters and might therefore require
HESSD

$5,95-145,2008$

\section{Soil parameter inversion - potential and limits}

A. Loew and W. Mauser

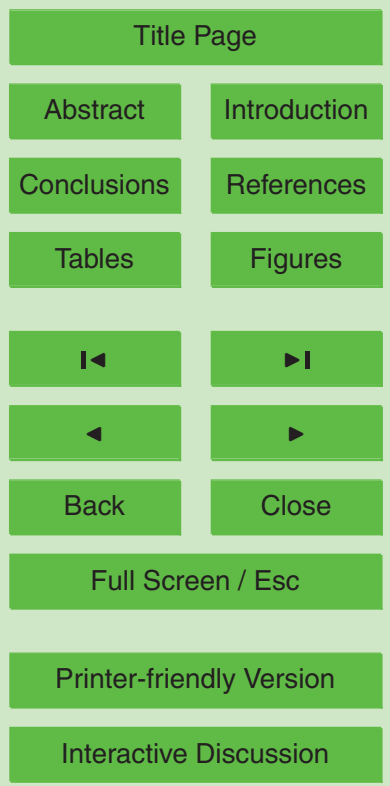

EGU 
constraints during the minimization procedure. Otherwise one might be able to find numerous solutions for a model parameter set which all results in model predictions that coincident well with observations. This problem has been addressed as the equifinality problem in parameter estimation (Beven and Binley, 1992; Beven and Freer, 2001).

$5 \quad$ While the direct measurement of soil hydraulic characteristics is hampered by complicated and costly measurements, indirect estimation of soil hydraulic properties is widely established. Soil pedotransfer functions (PTF's) use soil variables that can be easily measured (soil texture, organic matter) to estimate soil hydraulic characteristics. There are a couple of reviews on PTF's in the literature (Woesten et al., 2001; 10 Woesten, 1997; Rawls et al., 1991). Pedotransfer functions are typically statistical relationships between soil textural parameters and the soil hydraulic characteristics and are estimated from the analysis of large soil data bases (Woesten et al., 1999; Batjes, 1996). However, the required soil texture information is available with different accuracies at different spatial scales. Global soil data is available e.g. from the FAO map 15 (FAO, 1991) which provides soil texture data for the entire globe at very coarse spatial scales (1:5000 000), while much more detailed (e.g. scale 1:25000) information might be available only for limited areas.

Recent studies have shown that the combination of land surface model simulations and soil moisture observations might be used to infer information on soil characteristics 20 (de Lannoy et al., 2006; Vrugt et al., 2005; Lee, 2005; Santanello et al., 2007). These are based on continuous observations of soil moisture dynamics and corresponding land surface model simulations.

While in situ measurements provide accurate estimates of soil water content, continuous records are limited to few locations on the globe (Robock et al., 2000). Re25 mote sensing methods provide the opportunity to capture soil moisture dynamics at regional and global scales with different temporal frequencies and accuracies (Loew et al., 2006; Loew, 2008; Wagner et al., 2007a; Dubois et al., 1995). Microwave remote sensing techniques are predestinated for the retrieval of soil moisture information from space due to their high sensitivity to (surface) soil water content and as they are

\section{HESSD}

$5,95-145,2008$

\section{Soil parameter inversion - potential and limits}

A. Loew and W. Mauser

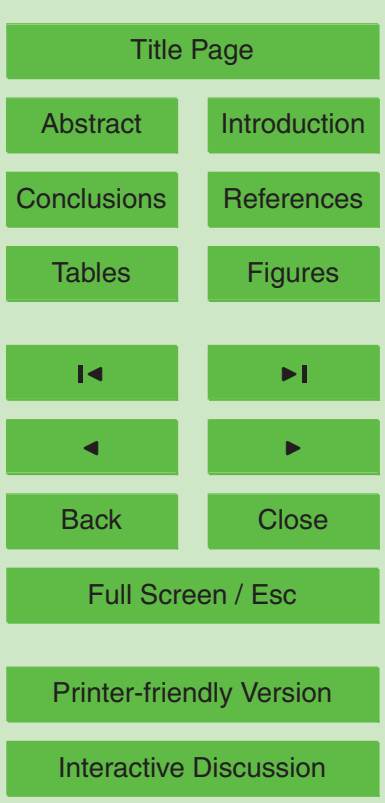

EGU 
independent from atmospheric or illumination conditions which allows for a continuous monitoring of the land surface. However, soil moisture retrievals from operational satellites are limited due to vegetation and surface roughness effects which might result in ambiguous retrievals of soil water content. Wagner et al. (2007b) give a comprehen5 sive overview about the applicability of different remote sensing sensors for the retrieval of soil moisture for hydrological applications. The accuracy of the retrievals from microwave sensors is highly dependent on the effect of vegetation on the one hand side and the sensors specifications (frequency, polarizations, imaging geometry, spatial resolution) on the other hand. The rms error of soil moisture retrievals might cover a wide o range from 0.02 to $0.10\left[\mathrm{~cm}^{3} / \mathrm{cm}^{3}\right.$ ] (Loew et al., 2006; Wagner et al., 2007a).

Recent microwave and thermal infrared remote sensing techniques are only sensitive to the soil water content of the upper soil layer. Dependant on the observing system configuration, the sensitive layer is within the uppermost $1 \ldots 10 \mathrm{~cm}$, whereas the penetration depth is also dependent on the soil water content itself. However it has been shown that the assimilation of observations of surface soil moisture information into hydrological models can result in improved predictions of soil water profiles (Enthekabi et al., 1994; Walker et al., 2001; Reichle and Koster, 2005; Reichle et al., 2001); Loew, $2008^{1}$. Future remote sensing missions as e.g. the forthcoming SENTINEL-1 satellite (Attema, 2005) will provide observations of the land at high spatial $(<100 \mathrm{~m})$ and high temporal ( $<3$ days) resolutions which would allow for frequent and continuous observations of land surface dynamics. However it is likely that hydrological applications might only benefit from remote sensing observations when the derived information matches certain quality standards in terms of accuracy and observation frequency.

The present paper therefore examines the potential to infer soil information through 25 inverse modeling by combining land surface model simulations with surface soil moisture observations. The basic objective is to exploit time series of surface soil moisture information to improve land surface model parameterization schemes. The questions

\footnotetext{
${ }^{1}$ Loew, A.: Assimilation of surface soil moisture information for improved land surface mod-

${ }^{1}$ Loew, A.: Assimilation of surface soil moisture information for improved land surface mod-
elling - requirements for satellite observations, Adv. Water Res., in review, 2008.
}

\section{HESSD}

5, 95-145, 2008

\section{Soil parameter inversion - potential and limits}

A. Loew and W. Mauser

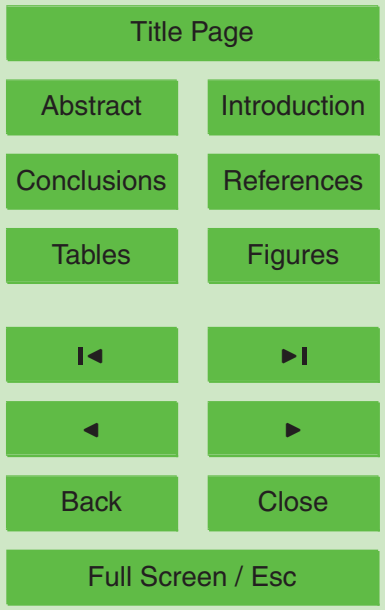

Printer-friendly Version

Interactive Discussion 
to be addressed are a) whether remote sensing derived surface soil moisture information might be in general useful to infer soil characteristics, b) which accuracies of the remote sensing data and $c$ ) which temporal frequencies are needed to achieve an improved parameterization of a land surface model.

5 The analysis is made using an inverse modeling approach which minimizes the deviations between observations of surface soil moisture and model predicted water content by altering land surface model parameters that describe the hydraulic characteristics of the soil.

The analysis is conducted using field data collected within the scope of the AGRISAR 2006 remote sensing campaign (Hajnsek et al., 2007) in Northern Germany. The current state of modeling water movement in the unsaturated zone is described briefly in Sect. 2. The inverse modeling approach is introduced in Sect. 3 and data and used models are presented in Sect. 4. The inverse modeling approach is given in Sect. 5 and results of the sensitivity analysis is presented in Sect. 6 .

\section{Materials and methods}

Consider a time-variant process model $\Phi$, that propagates the model state $x_{i}$ as

$x_{i}=\Phi\left(x_{i-1}, p, u_{i}, w_{i-1}\right)$

where $i$ denotes the time, $u_{i}$ is the vector of meteorological forcings and $p$ is the model parameterization and $w_{i}$ is a random process noise. Model parameters $p$ have to be measured in the field or models are often calibrated for specific sites using local ground observations. Mapping the model state space to the model output space, using the observation operator $H_{i}$ yields to the observation $y_{i}$ as

$y_{i}=H_{i} x_{i}+v_{i}$

whereas $H_{i} x_{i}$ corresponds to model predicted measurements. These might be direct 25

(e.g. soil moisture) or indirect (e.g. radiances of a satellite) measurements. In case that

\section{HESSD}

$5,95-145,2008$

\section{Soil parameter} inversion - potential and limits

A. Loew and W. Mauser

Title Page

Abstract

Introduction

Conclusions

Tables

References

Figures

14

4

Back

Close

Full Screen / Esc

Printer-friendly Version

Interactive Discussion 
$y_{i}$ is a direct observable of the model state vector $x_{i}, H_{i}$ contains only elements of 0 and 1 . The vector $v_{i}$ reflects the uncertainties of the measurement process. It might comprise uncertainties in the observation process, model forcing data, model physics and uncertainties in the model parameterization.

5 Most current approaches to data assimilation are derived from either a direct observer or dynamic observer technique. While the direct observer approach assimilates sequentially information at various time steps of the model, the latter attempts to find the best fit between model simulations and observations over an entire time series of observations (Walker and Houser, 2005). The dynamic observer technique might be formulated using either a strong or weak constraint assumption on the uncertainties of the model simulations $w$. In case of the strong constrained assumption, the process description of the physical model $\Phi$ is considered to be perfect, while weak constraint is where the uncertainties in the model formulation are taken into account as process noise.

15 In the present study we only focus on the uncertainties which are due to measurement errors and model parameterization. Thus a perfect model (strong constraint) is assumed in the scope of the present study $(w=0)$. The model parameter vector $p$ is assumed to be unknown and measurement errors $v$ are taken into account, assuming white noise.

\subsection{Water movement in the unsaturated zone}

The one-dimensional water movement in a partially saturated rigid porous medium might be described by the Richard's equation as (Richards, 1931)

$\frac{\partial \theta(z, t)}{\partial t}=\frac{\partial}{\partial z}\left[K(\theta, z)\left(\frac{\partial h(\theta, z)}{\partial z}-1\right)\right]$

where $h$ is the soil water pressure head $[\mathrm{m}], \theta$ is the volumetric water content $25\left[\mathrm{~cm}^{3} / \mathrm{cm}^{3}\right], t$ is time $[s], z$ is the spatial coordinate $[m]$ and $K$ is the unsaturated hydraulic conductivity function $\left[\mathrm{m} \mathrm{s}^{-1}\right]$. The unsaturated soil hydraulic properties $\theta(h)$
HESSD

$5,95-145,2008$

\section{Soil parameter} inversion - potential and limits

A. Loew and W. Mauser

Title Page

Abstract Introduction

Conclusions

Tables References Figures

14

$>1$

4

Back

Close

Full Screen / Esc

Printer-friendly Version

Interactive Discussion 
and $K(h)$ are generally non-linear functions of pressure head $h$. The Brooks and Corey formulations relate $K(h)$ and $\theta(h)$ to soil hydraulic characteristics as (Rawls and Brakensiek, 1985; Brooks and Corey, 1964)

$\frac{\theta-\theta_{r}}{\phi-\theta_{r}}=\left(\frac{h_{b}}{h}\right)^{\lambda}$

${ }_{5} K(\theta)=K_{s}\left(\frac{\theta-\theta_{r}}{\phi-\theta_{r}}\right)^{3+2 \lambda}$

where $\lambda$ is the pore size distribution index, $\theta_{r}$ is the residual water content, $h_{b}$ the bubbling pressure head, $\phi$ the soil porosity and $K$ is the fully saturated conductivity $(\theta=\phi)$. Equation (4) is also often referred as water retention curve.

\subsubsection{Pedotransfer functions}

10 Since direct measurements of soil hydraulic properties are time consuming, expensive and not feasible at larger scales, alternative approaches to the estimation of soil hydraulic properties using pedotransfer functions (PTF) have been developed. PTF's use easily measurable soil properties such as grain size or organic matter content to indirectly determine soil hydraulic characteristics. A variety of PTF's have been proposed based on field measurements. As every PTF was developed on the basis of a limited soil database, there is a lot of uncertainty in applying PTF's to different soil conditions under which it was developed. It might be therefore reasonable to take into account these uncertainties in an optimisation procedure to infer hydrological model parameters.

Woesten et al. (2001) reviewed the current status of PTF's and their accuracy and uncertainty. It was found that the uncertainty of the water retention curve in predicting actual soil water content using different PTF's ranged in the order of 2 to $11 \mathrm{vol} . \% \mathrm{rms}$ error. Wagner et al. (2001) evaluated eight different PTF's for the estimation of soil

\section{HESSD}

$5,95-145,2008$

\section{Soil parameter inversion - potential and limits}

A. Loew and W. Mauser

Title Page

Abstract

Introduction

Conclusions

References

Tables

Figures

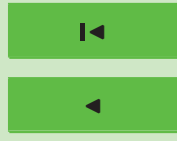

$\rightarrow$

Back

Close

Full Screen / Esc

Printer-friendly Version

Interactive Discussion 
hydraulic conductivity and found that the PTF of Woesten (1997) performed best for predicting the unsaturated hydraulic conductivity.

Given a set of soil texture parameters one might obtain different values for the soil hydraulic properties which will directly reflect on the simulations of a hydrological model. 5 Various PTF's are therefore used in the present study. Table 1 summarizes the PTF's which are used for the different model parameters within the present study.

\section{Inverse modeling of soil characteristics}

\subsection{Retrieval algorithm}

In this section, the basis of the retrieval algorithm to estimate soil texture as well as

soil hydraulic properties from surface soil moisture observations is introduced. The retrieval is based on a numerical minimization of a cost function that accounts for the differences between the soil moisture predictions of a land surface model and surface soil moisture observations. Two general cases are considered: 1) direct retrieval of soil hydraulic properties $\left(h_{b}, \phi, \theta_{r}, K_{s}, \lambda\right)$ and 2) retrieval of soil texture information as 15 sand and clay fraction $S, C$, whereas soil hydraulic properties are estimated throughout PTF's.

Different cost functions might be applied in that context using either only informations about observation uncertainties or explicitly take into account potential uncertainties in the model parameters. In the latter case, the uncertainties of the model parameters

\section{HESSD}

$5,95-145,2008$

\section{Soil parameter inversion - potential and limits}

\section{A. Loew and W. Mauser}

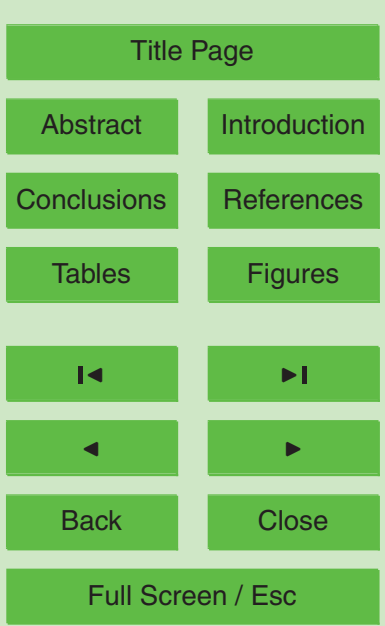

Printer-friendly Version

Interactive Discussion the physical model to best reproduce the observed soil moisture dynamics. 
The unknown soil characteristics are represented by a vector $p=\left[\lambda, K_{s}, \theta_{r}, \phi, h_{b}\right]^{T}$ Given a vector of soil moisture observations $y$, the probability density function (pdf) of $p$ conditioned by the observations $y$ is using Bayes's theorem

$P(p \mid y) \propto P(y \mid p) P\left(p \mid p_{0}\right)$

5 where $P\left(p \mid p_{0}\right)$ is the pdf of $p$ given its prior estimate $p_{0}$. We assume that the error of $p$ is zero mean Gaussian, so that

$p=p_{0}+\epsilon_{p}$

where $\epsilon_{p}$ is the gaussian distributed parameter error. The probability function of $p$ subject to a prior estimate $p_{0}$ is then

$P\left(p \mid p_{0}\right) \propto \exp \left[-0.5\left(p-p_{0}\right)^{T} G^{-1}\left(p-p_{0}\right)\right]$

where $G$ is the diagonal covariance matrix. Additionally, the observations $y$ are considered to be affected by measurement errors $v \in N(0,1)$. Gaussian error statistics is also assumed here. The probability of measuring a certain $y$ given a model parameter set $p$ is given by

$P(y \mid p) \propto \exp \left[-0.5(y-H x(p))^{T} S^{-1}(y-H x(p))\right]$

where $S$ is the diagonal covariance matrix. Substituting (8) and (9) into (6) yields the Bayesian likelihood function as

$$
\begin{gathered}
P(p \mid y) \propto \exp \left[-0.5(y-H x(p))^{T} S^{-1}(y-H x(p))\right. \\
\left.-0.5\left(p-p_{0}\right)^{T} G^{-1}\left(p-p_{0}\right)\right]
\end{gathered}
$$

Since maximizing (10) is equivalent to minimize $-\ln (P(p \mid y))$, the maximum likelihood estimator of $p$ is obtained by minimizing the following cost function (Pulliainen et al.,

\section{HESSD}

$5,95-145,2008$

Soil parameter inversion - potential and limits

A. Loew and W. Mauser

Title Page

Abstract

Introduction

Conclusions

References

Tables

Figures

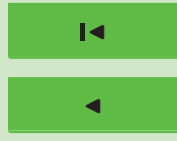

$\rightarrow$

Back

Close

Full Screen / Esc

Printer-friendly Version

Interactive Discussion 


$$
\begin{array}{r}
J=0.5(y-H x(p))^{T} S^{-1}(y-H x(p)) \\
+0.5\left(p-p_{0}\right)^{T} G^{-1}\left(p-p_{0}\right)
\end{array}
$$

Many different minimization algorithms (e.g. Levenberg-Marquardt, Nelder-mead5 simplex) might be used to minimize the cost function $J$ (Nelder and Mead, 1965). When no prior information on the model parameters $p_{0}$ is available, $P\left(p \mid p_{0}\right)$ can be dropped and (11) reduces to it's first term which represents the traditional minimization of mean square error

$J=0.5(y-H x(p))^{T} S^{-1}(y-H x(p))$

\section{$10 \quad 3.3$ Accuracy assessment}

To quantify the accuracy of the physical model predictions, the time series of model predictions and measurements are compared. Different benchmarks are employed to quantify the impact of the model parameterization on the model simulations. The used benchmarks are the root mean square error (rmse) [vol.\%] and model efficiency $E$ [-].

The comparisons are made on the basis of hourly values The rmse is calculated as

rmse $=\sqrt{\frac{\sum\left(y_{i}-H x_{i}\right)^{2}}{n}}$

where $n$ is the number of observations and $y$ and $H x$ are the measured and predicted observations (e.g. soil moisture) respectively. The model efficiency $(E)$ is estimated as (Nash and Sutcliffe, 1970)

$20 \quad E=1-\left[\frac{\sum\left(y_{i}-H x_{i}\right)^{2}}{\sum\left(y_{i}-\mu\right)^{2}}\right]$

where $\mu=E[y]$ is the expected value of $y$. The model efficiency can range between $-\infty$ and 1, whereas positive values of $E$ indicate that the time series better represents the

\section{HESSD}

$5,95-145,2008$

\section{Soil parameter} inversion - potential and limits

A. Loew and W. Mauser

Title Page

Abstract

Introduction

Conclusions

References

Tables

Figures

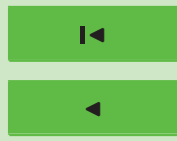

$\rightarrow$

Back

Close

Full Screen / Esc

Printer-friendly Version

Interactive Discussion 
dynamic of the investigated parameter than a mean value. Perfect agreement between the reference dataset and the simulations is achieved for $E=1$.

\section{Data and models}

\subsection{Land surface model}

5 The Process Oriented Multiscale EvapoTranspiration model (PROMET) is used within the present study to simulate water and energy fluxes. It is a family of land-surfaceprocess-models which describe the actual evapotranspiration and water balance at different scales, ranging from point scale, to micro- and mesoscale (Mauser and Schaedlich, 1998). The model consists of a kernel model which is based on five sub10 modules (radiation balance, soil, vegetation, aerodynamic model, snow) to simulate the actual water and energy fluxes and a spatial data modeller, which provides and organizes the spatial input data on the field-, micro- and macroscale. The simulations are made on an hourly basis.

Actual evapotranspiration is simulated within PROMET using the Penman-Monteith 15 equation (Monteith, 1965). Canopy surface resistance is simulated as a function of vegetation type using a resistance network approach (Baldocchi et al., 1987), while the soil resistance is estimated based on the approach of Eagleson (1978). A three layer soil model $(0-10,10-30,30-150 \mathrm{~cm})$ is used to represent the soil water fluxes. The soil water retention model of Brooks and Corey (1964) is used to relate soil moisture content to soil suction head.

A ten layer vegetation model is used to convert the incoming radiation into fractions of shaded and sunlit leaves (Norman, 1979). A detailed description of the model is given by Mauser and Schaedlich (1998). A physical snow model extends PROMET to allow for simulations in cold climates (Strasser and Mauser, 2001). Vegetation development is considered by prescribing the evolution of vegetation height, albedo and leaf area index as a function of the day of the year. This allows for a flexible parameterisation of

\section{HESSD}

$5,95-145,2008$

\section{Soil parameter} inversion - potential and limits

A. Loew and W. Mauser

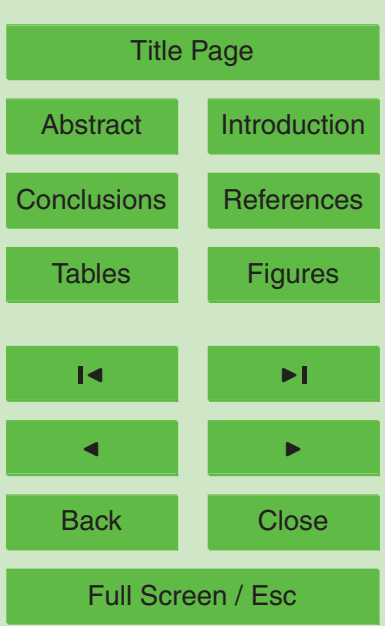

Printer-friendly Version

Interactive Discussion 
vegetation parameters.

PROMET simulations are based on GIS information as e.g. soil and land cover maps. Meteorological forcing data might be either provided from point like station measurements as well as gridded forcing fields. PROMET has been extensively validated in 5 different geographic regions (Upper Rhine Valley $-100 \mathrm{~km}^{2}$, Bavarian Alpine Foreland $-20000 \mathrm{~km}^{2}$, Upper Danube catchment $-76000 \mathrm{~km}^{2}$, Weser catchment $-35000 \mathrm{~km}^{2}$, India $-400 \mathrm{~km}^{2}$ ) using evapotranspiration measurements of micrometeorological stations at the local scale and by comparison with thermal remote sensing informations at the regional scale (Mauser and Schaedlich, 1998; Ludwig and W., 2000; Pauwels et al., 2008); Loew, $2008^{1}$.

\subsection{Field data}

\subsubsection{Test site}

The present study has been performed in the framework of the AgriSAR 2006 campaign, for which the test site was located in North-East Germany, approximately $150 \mathrm{~km}$ 15 North of Berlin. Hajnsek et al. (2007) give a detailed description of the campaign. Only a short description will be given here. The test site is based on a group of farms within a farming association covering approximately $250 \mathrm{~km}^{2}$. Field sizes are very large in this area, averaging between 2 and $2.5 \mathrm{~km}^{2}$. The main crops are winter wheat, winter barley, winter rape, corn, and sugar beet. The altitudinal range within the test site is approximately $50 \mathrm{~m}$.

\subsubsection{Meteorological data}

The meteorological data to drive PROMET is obtained from an agrarmeteorological weather station (Goermin, $53.98 \mathrm{~N} / 13.26 \mathrm{E}$ ). The station records meteorological data at $10 \mathrm{~min}$ frequency. The station is expected to provide best information on the local

\section{HESSD}

$5,95-145,2008$

\section{Soil parameter} inversion - potential and limits

A. Loew and W. Mauser

Title Page

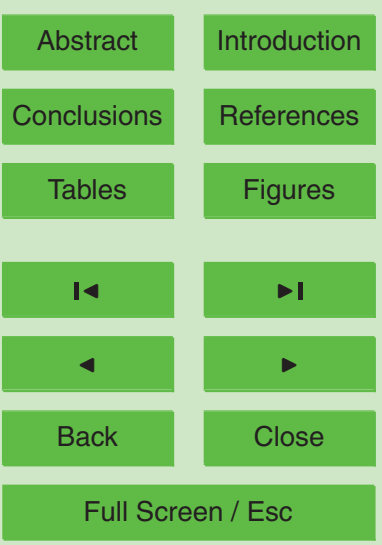

Printer-friendly Version

Interactive Discussion 
Meteorological inputs are the major model drivers, thus their accuracy directly reflects on the uncertainties of the model results. Loew $2008^{1}$ has shown that inaccurate estimates of meteorological input might result in large uncertainties of land surface model simulations. However reasonable results were found, when using local forcing 5 data for the model simulations (Pauwels et al., 2008). This gives us confidence that the strong constraint assumption of minor model error can be used within the present study. However, this assumption might probably not hold in case that forcing data might have much higher uncertainties.

\subsubsection{Soil moisture measurements}

10 Numerous field measurements and remote sensing data has been collected during the investigation period which lasted from April to July 2006,. Continuous measurements of soil moisture were recorded within a wheat field. Soil water content was measured using TDR soil moisture probes (IMKO TRIME-ES), which were installed in depths of $5,9,15,25$ and $47 \mathrm{~cm}$. The measurements were conducted within the period from 19 15 April 2006 (JD 109) to 06 July 2006 (JD 187). The wheat plants were at tillering stage during the installation of the station and have reached the dough development stage at the end of the measurement period in accordance with the EUCARPIA code for cereals (Zadoks et al., 1974). Figure 1 shows the recorded soil moisture profiles. Soil moisture was homogeneous within the soil at the beginning of the measurement period, with 20 values around $24 \%\left[\mathrm{~cm}^{3} / \mathrm{cm}^{3}\right]$. Except the uppermost soil layer $(5 \mathrm{~cm})$ shows slightly reduced values $\left(\sim 20 \% \mathrm{~cm}^{3} / \mathrm{cm}^{3}\right)$. A first considerable precipitation event is observed between JD 136 and JD 145, where $20 \mathrm{~mm}$ precipitation were recorded. This results in an increase of the soil moisture content of the first $10 \mathrm{~cm}$. A second precipitation event $(27 \mathrm{~mm})$ is observed between JD 148 and JD 156, which has also an impact on the soil 25 moisture measurements at $25 \mathrm{~cm}$ depth. A 12 day period without precipitation follows. Another rainfall of $24 \mathrm{~mm}$ is observed within the period from JD 168 to JD 173, which only results in a recharge of the upper soil layer $(0-10 \mathrm{~cm})$. The lowermost $(47 \mathrm{~cm})$ soil moisture measurements remain almost unaffected by the precipitation events. Stable

\section{HESSD}

5, 95-145, 2008

Soil parameter inversion - potential and limits

A. Loew and W. Mauser

Title Page

Abstract

Introduction

Conclusions

Tables

References

Figures

14

-1

4

Back

Close

Full Screen / Esc

Printer-friendly Version

Interactive Discussion 
soil moisture values are observed from JD 110 to JD $125\left(25 \% \mathrm{~cm}^{3} / \mathrm{cm}^{3}\right)$. Afterwards, the soil moisture of the lower soil layer shows an almost linear decrease until the end of the measurement period.

\subsubsection{Soil information}

5 Soil samples were taken in the investigated field at three different locations. The samples were analysed in the laboratory and the grain size of the soil particles was determined. The total sand content is $57.2 \pm 1.3 \%$ and the clay content was estimated as $17.7 \pm 1.0 \%$, whereas the major grain size is fine sand $(200-63 \mu \mathrm{m})$. The FAO soil map (FAO, 1991) indicated a sand content of $51 \%$ and a clay content of $17 \%$ which is pretty 10 close to the laboratory measurements.

\section{Inverse modeling approach}

The inverse modeling of soil characteristics is based on the comparison between simulated and observed soil moisture time series. Model parameters are altered until best coincidence between model simulations and measurements is achieved. To infer soil characteristics from surface soil moisture observations the cost Functions (11) and (12) are minimized using an iterative solver (Nelder-Mead-Simplex). Figure 2 shows the general data flow of the approach. Surface soil moisture observations are taken from TDR measurements. These are sampled with different time intervals and various observation errors $v$ are assumed to mimic uncertainties in remote sensing derived surface soil moisture products. The PROMET model is used to simulate in a first step the soil water content for a given investigation period, given an initial model parameter set $p_{0}$ (initial guess). The model predictions $(H x)$ are then compared against the observations $y$. The parameter vector $p$ is iterated as long as no convergence is achieved. The minimization algorithm either minimizes directly the model soil hydraulic param-

\section{HESSD}

$5,95-145,2008$

\section{Soil parameter} inversion - potential and limits

A. Loew and W. Mauser

Title Page

Abstract

Introduction

Conclusions

Tables

References

Figures

14

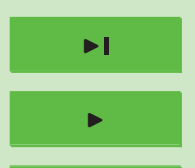

Back

Close

Printer-friendly Version

Interactive Discussion 
model parameters via the use of PTF's.

Finally, the resulting model simulations are compared against the soil moisture observations for the first $(0-10 \mathrm{~cm})$ and second $(10-30 \mathrm{~cm})$ PROMET soil layer. The TDR soil moisture measurements from 5 and $25 \mathrm{~cm}$ are used for that purpose respectively.

\section{$5 \quad 5.1$ Model setup}

\subsubsection{Observation setup}

It is expected that the temporal frequency as well as quality of the soil moisture observations will affect the capability of estimating a reliable value for $p$. To explicitly investigate that impact, different subsets are extracted from the surface soil moisture 10 measurements. These subsets are sampled with different temporal frequencies to simulate the case of different observation frequencies of a sensor system. This sampling was made at hourly and daily frequencies, increasing from one day to 14 days, resulting in a total of 15 different time steps $k$.

Random gaussian error was added to each of these data sets to imitate various qual15 ities of surface soil moisture observations. The standard deviation of the observation error was set to $1,2,4,6$ vol. $\%\left[\mathrm{~cm}^{3} / \mathrm{cm}^{3}\right]$, which covers a realistic range of uncertainties as it could be expected from remote sensing satellite data (Wagner et al., 2007a; Loew, 2008).

\subsubsection{Prior soil information}

In case that prior information on soil properties is available, these might be used to constrain the minimization algorithm. This prior information can be derived either from field measurements or secondary sources as soil texture maps. The latter is used within the present study. The FAO soil map (FAO, 1991), which is generally globally available, was used to estimate the first guess for the soil texture vector $m=[s, c]^{T}$. This initial guess is used to estimate the background probability for the model parameter vector $p$ which

\section{HESSD}

$5,95-145,2008$

\section{Soil parameter} inversion - potential and limits

A. Loew and W. Mauser

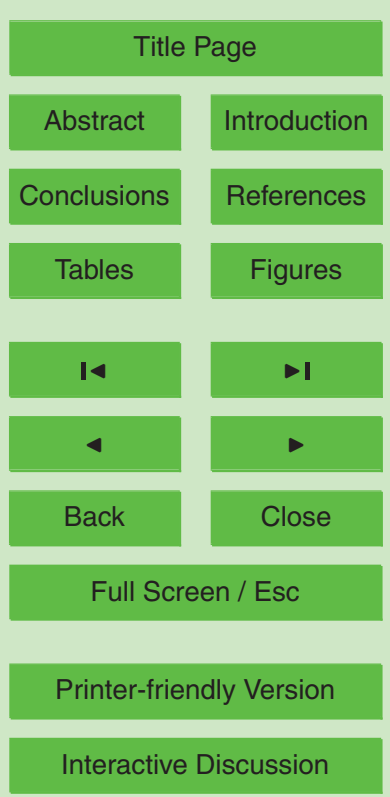

EGU 
requires the estimation of $p_{0}$ and $\epsilon_{p}$. These are obtained from a monte carlo based sampling of the parameter space. As it is assumed that the FAO map might be highly uncertain, we assume a standard deviation $\sigma_{p}$ which guarantees that also soil texture combinations which are far from the initial guess contribute to the calculation of $p_{0}$ 5 and $\sigma_{p}$. This yields to the normal distributed ensemble matrix $M_{2 \times N}=\left[\boldsymbol{m}_{1}, \boldsymbol{m}_{2}, \ldots, \boldsymbol{m}_{N}\right]$ where $N$ is the number of ensemble members and was assigned a value of 1000 in the present study.

To take into account the uncertainties of the PTF functions, different PTF's are applied for each model parameter. For each $\boldsymbol{m}$, a set of different model parameters $10\left(\lambda, K_{s}, h_{b}, \theta_{r}, \phi\right)$ is obtained using PTF's from different sources (Table 7$)$. This results in an ensemble of 1000 values for the bubbling pressure head $h_{b}, 1000$ values for the pore size distribution index $\lambda, 4000$ values for $K_{s}, 3000$ values for the porosity $\phi$ and 2000 values for the residual water content $\theta_{r}$.

This ensemble of the model parameters is then used to calculate the mean and variance for each model parameter which gives the prior guess on the model parameters $p_{0}$ and the associated covariance matrix $G$ in Eq. (8). The obtained statistics for the $p_{0}$ parameters are given in Table 3.

\subsubsection{Open loop simulations}

PROMET simulations are made using the prior information on soil parameters, as de20 rived from either the laboratory measurements (LAB) or the FAO classification (FAO). These simulations indicate the capabilities of the LSM to simulate soil water fluxes using only a priori information without any observation data. To assess the impact of different PTF's on the model simulations, various PTF's are applied to derive saturated hydraulic conductivity $K_{s}$ from the laboratory measurements.

25 The soil moisture simulations, using the laboratory measurements and FAO data for the model parameterization, are shown in Fig. 3. The model simulations agree well with the measured soil water content and minor differences are observed between the different model realizations (rmse: 3.05 vol.\%). However the model tends to underesti-

\section{HESSD}

5, 95-145, 2008

\section{Soil parameter} inversion - potential and limits

A. Loew and W. Mauser

Title Page

Abstract Introduction

Conclusions

Tables

References

Figures

14

$\rightarrow$

4

Back

Close

Full Screen / Esc

Printer-friendly Version

Interactive Discussion 
mate the soil water content in the spring period which might be attributed to the fact that there was a snow cover in the study area until the end of March 2006 resulting in rather wet soil condition. PROMET simulations underestimated snow cover in spring and the soil moisture in the model therefore shows a negative bias. Nevertheless, the model 5 shows a good performance also for the FAO data throughout the investigation period which is due to the fact that the a priori information on the soil texture, taken from the FAO map, is in considerable agreement with the field measurements of grain size. In case that the FAO information would stronger deviate, much higher uncertainties in the model simulations can be expected. The soil moisture rms error as well as the model 10 efficiency for these open loop simulations are given in Table 2 for the upper $(5 \mathrm{~cm})$ and lower $(25 \mathrm{~cm})$ soil layer, respectively.

\subsection{Model simulations}

The prior model parameters $p_{0}$ are used to initialise PROMET. The simulations are made from 1 January 2005 to 30 June 2006. The first model year is used for model spin-up, while the comparisons and assimilation of soil moisture obs
done for the period from 20 April (JD 110) to 5 July 2006 (JD 186).

Only the surface soil moisture $(5 \mathrm{~cm})$ observations are used as measurement variable, while the deeper soil moisture observations are only used for accuracy assessment. Surface soil moisture observations were used every $\Delta t$ time steps which results

$\boldsymbol{y}=\left[\theta_{1}, \theta_{2}, \ldots, \theta_{N}\right]^{T}$

whereas $\theta_{k}$ corresponds to the surface soil moisture observations at time $k$. The PROMET model state vector $\boldsymbol{x}_{i}=\left[\theta_{L 1}, \theta_{L 2}, \theta_{L 3}\right]^{T}$ contains the PROMET soil moisture predictions within the three different soil layers. As only surface soil moisture measurements are considered, the surface soil moisture predictions form the $\mathrm{N}$-dimensional multitemporal vector

$\boldsymbol{x}_{i}=\left[\theta_{L 1,1}, \theta_{L 1,2}, \ldots, \theta_{L 1, N}\right]^{T}$

\section{HESSD}

$5,95-145,2008$

\section{Soil parameter} inversion - potential and limits

A. Loew and W. Mauser

Title Page

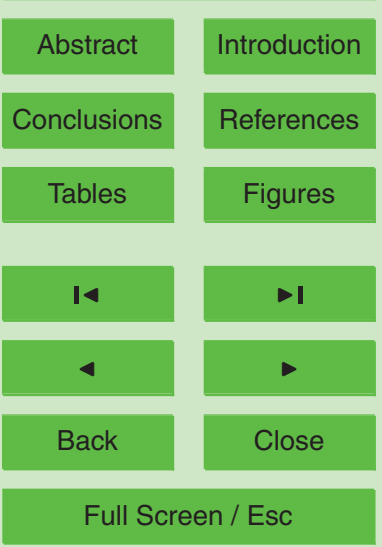

Printer-friendly Version

Interactive Discussion 
As the soil moisture measurements and the PROMET states represent the same physical parameter (soil moisture [vol.\%], 0-10 cm depth), the observation operator $H$ in (2) reduces to a matrix with only 0 and 1 as elements. To analyse the effects of constraints on the model parameters on the one hand side and to investigate the importance of 5 prior soil texture information from secondary data on the other hand, the following different model scenarios are investigated:

- Scenario A: Direct determination of soil hydraulic parameters: the soil hydraulic characteristics are assumed to be unknown. The objective function is minimized by modifying $p=\left[\lambda, K_{s}, \phi, h_{b}, \theta_{r}\right]^{T}$.

- Scenario B: Inverse modeling of soil texture using PTF's without constraints on model parameters: Sand and clay content are considered as free model parameters $\left(\boldsymbol{m}=[s, c]^{T}\right)$. Soil hydraulic characteristics are obtained from PTF's, whereas the uncertainties in the model parameters are not considered in the cost function (Eq. 12)

- Scenario C: Inverse modeling of soil texture using PTF's with constraints on model parameters: same as scenario $B$, but uncertainties in the model parameterisation are considered in the cost function (Eq. 11).

An appropriate initialisation of model parameters is important to minimize the risk that the minimization algorithm gets stuck in a local minima while searching for the optimal parameter set. To investigate the robustness of the parameter inversion approach, two different cases are investigated for the scenarios $B$ and $C$. The first assumes that a priori information on soil texture is available from some source, while the other assumes that no a priori information is given. For the first the information from the FAO classification is used while standard values of $s=30 \%$ and $c=30 \%$ are assumed for the second.

25 These scenarios are referred as $(B 1, C 1)$ and $(B 2, C 2)$, respectively. A summary of model scenarios, used parameterisation and cost functions is given in Table 3.

For each of the five scenarios the inverse modeling approach was applied for the 5

\section{HESSD}

$5,95-145,2008$

\section{Soil parameter} inversion - potential and limits

A. Loew and W. Mauser

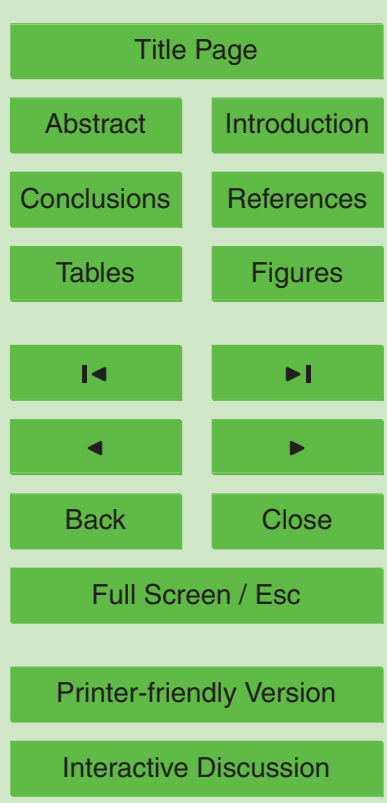

EGU 
different measurements errors and 15 temporal sampling frequencies $\Delta t$ which results in 75 simulation runs per scenario and thus in a total number of 375 simulations.

\section{Results}

\subsection{Inverse modeling of soil texture using PTF's (constrained case)}

5 The results of the inversion of soil texture $(s, c)$ by integrating surface soil moisture information is investigated in this section. Figure 7 shows the inversion results for clay and sand respectively for different temporal frequencies and observation errors. Table 4 summarizes the mean and standard deviation of the retrieval residues using the laboratory soil texture data as reference value. Given an appropriate initial guess for 10 soil texture from the FAO map (B1,C1), the retrieved soil texture matches the sand and clay content very well. The mean error is $0.54(0.75)$ and $0.43(0.38)$ for the B1 and C1 scenario respectively for clay (sand) content. No distinct dependency on the temporal sampling or observation error is observed. However, given a less accurate initial guess for soil texture (B2,C2), the uncertainties in the soil texture retrievals considerably increase. For low observation errors (1 vol.\%), best retrieval results are observed. When increasing the observation uncertainty, the uncertainties in the soil texture retrievals also increase. Especially for high observation uncertainties large residues are observed, resulting in a mean error of -14.22 and -13.55 for the B2 and C2 simulation for sand respectively, while the residues of clay content are 2.01 and 3.06. This indicates that the retrievals give a higher weight to the silt content. From the analysis of the field data it was found that fine sand and silt are the major fraction of the investigated soil. Thus the high deviations for sand do not necessarily imply a worse performance of the algorithm.

In both cases the consideration of uncertainties in the soil hydraulic parameters using 25

\section{HESSD}

5, 95-145, 2008

\section{Soil parameter} inversion - potential and limits

A. Loew and W. Mauser

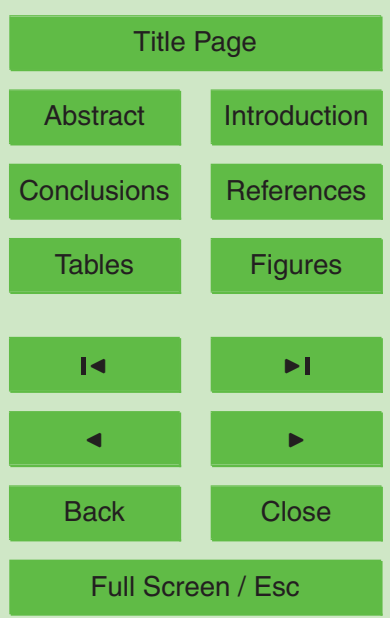

Printer-friendly Version

Interactive Discussion 


\subsection{Impact of temporal sampling and observation error}

It has been shown that the temporal sampling of the observations has a minor impact on the accuracy of the soil texture retrievals. Figure 5 shows the soil moisture profiles for four different runs of the $\mathrm{C} 1$ scenario, using observations with daily, 4-day, 7-day and 5 14-days sampling. It can be seen that there are only minor differences between the individual model runs which indicates that the soil texture used for the model simulations matches quite well the expected value. However deficits in the model parameterization can also be observed. In case of dry soil conditions, the model is not able to simulate the low soil moisture observations and saturate at a low soil moisture content of approximately $11 \mathrm{vol} . \%$, while the observed values show a further decrease of the soil water content. This might be explained by an underestimation of the soil hydraulic conductivity $\left(K_{s}\right)$ using the PTF functions. Further discussion will be given in Sect. 6.3.

An increasing uncertainty of the observations results in positive bias of the model predictions as shown in Fig. 6 for the $\mathrm{C} 1$ scenario.

\subsection{Error analysis}

The error in the model soil moisture predictions is expressed for the investigation period in terms of the soil moisture rms error and model efficiency $E$. Figure 7 shows the obtained rms errors and model efficiencies for all combinations of observation errors and sampling frequencies for the $\mathrm{C} 1$ scenario. The mean and standard deviation are $3.5(0.3)$ and $0.62(0.07)$ for the surface soil moisture rms error and model efficiency, respectively. As it has been shown that the open loop simulations, using the FAO data as a reference, already provides good simulations for the investigated test site, the error benchmarks are normalized by the rms error and model efficiency obtained from the FAO open loop simulations (Table 2). The normalized error values are also shown

\section{HESSD}

$5,95-145,2008$

Soil parameter inversion - potential and limits

A. Loew and W. Mauser

Title Page

Abstract Introduction

Conclusions

Tables

References

Figures

14

-1

4

Back

Close

Printer-friendly Version

Interactive Discussion 
No systematic differences are observed between the different model errors or temporal sampling rates. Most simulations show a similar accuracy than the open loop simulation which might be attributed to the fact that the FAO soil texture information already provides quite accurate estimates of the soil texture within the study area. Us5 ing the FAO information as the initial guess (C1), no improvements are achievable by assimilating the observation data into the model.

\subsubsection{Constrained versus unconstrained}

To evaluate the impact of using the different cost functions (11) and (12), the results of the $\mathrm{B} 1$ and $\mathrm{C} 1$ scenarios are compared. Figure 8 shows the rms error and model efficiency for the two cases respectively. Only minor differences are observed between the two approaches. The rms error is 3.5 vol.\% in both cases and the mean model efficiency is 0.61 and 0.62 for the unconstrained and constrained example respectively.

Figure 9 shows the frequency distribution of the ratio of the two results for the rms error and model efficiency respectively. Values below unity indicate lower rms error or 5 model efficiency for the $\mathrm{B} 1$ scenario compared to the $\mathrm{C} 1$ scenario. The mean of the frequency distribution is 1.02 and 1.00 for the rms error and model efficiency which indicates again minor differences between the two modeling approaches. Thus the consideration of model parameter uncertainties in the cost function does not result in an improvement of the model simulations skills in the present case..

\subsubsection{Impact of a priori knowledge of soil characteristics}

It has been shown that the a priori information on local soil texture, obtained from the FAO map, is within a reasonable range compared to the laboratory measurements. As a result, the integration of surface soil moisture information into the process model has a minor impact on the model parameterization. However, it might be expected that less accurate a priori information might be available at other places. To assess the impact of the prior guess on soil characteristics obtained from the inverse modeling

\section{HESSD}

5, 95-145, 2008

\section{Soil parameter inversion - potential and limits}

A. Loew and W. Mauser

Title Page

Abstract

Introduction

Conclusions

Tables

References

Figures

14

$\rightarrow$

4

Back

Close

Full Screen / Esc

Printer-friendly Version

Interactive Discussion 
approach, the scenarios $\mathrm{C} 1$ (B1) can be compared against $\mathrm{C} 2$ (B2). Figure 10 shows the normalized rms error and model efficiency with and without a priori soil texture information. While similar accuracies are achieved for observation errors below 4 vol.\%, the accuracy of the model simulations becomes worse when increasing the observa5 tion uncertainty. That indicates that the minimization algorithm becomes more instable in finding the optimal solution for higher uncertainties of the observations. However, in case of observations with uncertainties $<4$ vol.\%, the obtained model predictions are in considerable agreement with those obtained from the open loop simulations which indicates that, given no first guess on soil texture, surface soil moisture informations 10 might provide useful information to improve the soil parameterisation in those cases.

\subsection{Inverse modeling of soil hydraulic parameters}

In case that soil hydraulic parameters are directly inferred and no constraints are applied to the retrieval by means of PTF's (scenario A), different simulation results might be obtained. Figure 7 shows simulation results using different observation frequencies and an observation uncertainty of $1 \%$ vol. It is observed, that the model simulations agree well with the TDR measurements. The soil moisture rms error is 1.7, 2.6, 2.1 and 2.9 for the daily, 4-day, 7-day and 14-day sampling interval respectively. Especially in case of low soil moisture values, the model simulations do much better match the observations which might be attributed by a better parameterization of the soil hydraulic 20 conductivity. In case of daily observations, the model best captures the measured soil moisture dynamics.

Figure 7 shows the rms error and model efficiency for scenario A. It is seen, that the obtained model simulations show a smaller rms error and higher model efficiency, compared to the simulations of scenario $B$ and $C$. The mean value for the normalized 25 rms error and model efficiency are 0.73 and 1.11 respectively, indicating that the integration of surface soil moisture information results in a more than $25 \%$ improvement compared to the open loop simulation (rms error).

However, a better model prediction does not necessarily imply that the obtained

\section{HESSD}

5, 95-145, 2008

\section{Soil parameter} inversion - potential and limits

A. Loew and W. Mauser

Title Page

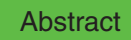

Introduction

Conclusions

Tables

References

Figures

14

I

4

Back

Close

Full Screen / Esc

Printer-friendly Version

Interactive Discussion 
model parameters are within a reasonable physical range. Table 5 therefore compares the retrieved soil hydraulic parameters against the direct predictions from the open loop simulations (FAO, laboratory) and corresponding literature values. The values taken from Rawls and Brakensiek (1985) are denoted in the first column and show a large 5 variability in the soil parameters within a specific soil type. For the inversion results, the mean and standard deviation are given.

The inversion results differ from the parameters one obtains using the FAO or laboratory soil texture information. However, the retrieved soil hydraulic parameters are within a reasonable range compared to the parameter range reported by Rawls and 10 Brakensiek (1985). Except the saturated soil hydraulic conductivity slightly exceeds the parameter range with a mean $K_{s}$ value of $6.96(\mathrm{~cm} / \mathrm{h})$. The higher values are required to better capture the water movement in the soil column.

\subsection{Impact on soil moisture profile}

An improved simulation of surface soil moisture content will also reflect on the simula15 tions of the soil water content in the deeper soil layers $(10-30 \mathrm{~cm})$. Thus an improved parameterization of the surface soil characteristics might also affect the soil moisture simulation skills of the deeper soil layers. Figure 7 shows measured and simulated soil moisture for the 10-30 cm layer for scenario A. Best model predictions are achieved for a daily assimilation which results in an rms error of $2.13\left(\mathrm{~cm}^{3} / \mathrm{cm}^{3}\right)$ and a model effi20 ciency of 0.86 which corresponds to a slight improvement compared to the open loop simulation (Table 2). Figure 7 shows the normalized rms error and model efficiency for the deeper soil layer. The mean rms error and model efficiency are $3.0\left(\mathrm{~cm}^{3} / \mathrm{cm}^{3}\right)$ and 0.71 with standard deviations of 0.60 and 0.11 respectively. Improved simulations (normalized rms $<1$ ) are achieved only in case of frequent and accurate measurements.

25 Approximately weekly observations with high accuracy $(v=1 \ldots 2$ vol.\%) are required to get an improvement compared to the open loop simulation. The higher the uncertainties in the observation, the higher the temporal sampling has to be. Only minor improvements are observed in case of observation errors greater than 4 vol.\%. Here

\section{HESSD}

$5,95-145,2008$

\section{Soil parameter} inversion - potential and limits

A. Loew and W. Mauser

Title Page

Abstract

Introduction

Conclusions

Tables

References

Figures

14

$\rightarrow 1$

4

Back

Close

Full Screen / Esc

Printer-friendly Version

Interactive Discussion 
2-day observation frequencies seem to be required to improve the model predictions. A frequent coverage seems to be most important to capture the dry end conditions of the data set to be able to better find a parameter set that best represents the soil moisture dynamics.

5 However, it is emphasized again that the reference open loop soil moisture simulation already matches well the observations. In case that the a priori information on soil texture might be much worse, the relative impact of integrating surface soil moisture data might be much higher and the model simulations might benefit more from observations with even higher uncertainties.

\section{Conclusions}

The present study has investigated the potential of using constrained and unconstrained inverse modeling approaches to infer soil hydraulic characteristics. It was assumed that uncertainties in the physical model simulations are only due to uncertainties in the model forcing data or model parameterization, but not due the models 15 process formulation.

Previous analysis of PROMET simulations (Pauwels et al., 2008); Loew $2008^{1}$ found that the model predictions of soil water and energy fluxes are in reasonable agreement with in situ data, which gives us confidence in that strong constraint assumption for the scope of this study. However, this assumption might be no longer valid if the model

driving meteorological forcing data has a higher uncertainty. In these cases, the additional uncertainties of the forcing data and its impact on the model simulations will have to be taken into account within the analysis Loew $(2008)^{1}$.

The conclusions that can be drawn from the analysis of the conducted experiment are

1. Constrained as well as unconstrained model parameter calibration strategies might result in reasonable predictions of the soil water fluxes by PROMET.

\section{HESSD}

$5,95-145,2008$

\section{Soil parameter} inversion - potential and limits

A. Loew and W. Mauser

Title Page

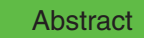

Introduction

Conclusions

Tables

References

Figures

14

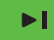

4

Back

Close 
2. Soil grain size might be infered by inverse modeling of surface soil moisture data.

3. However, an appropriate initial guess of the soil texture is critical for a robust estimate of soil characteristics. Otherwise the inversion algorithm is likely to get stuck in a local minima in case of observation errors $>4$ vol. $\%$.

4. The direct inversion of soil hydraulic parameters results in realistic model parameter retrievals. The direct calibration of model parameters outperforms the indirect approach using PTF's.

5. An improved model parameterization using surface soil moisture information might be used to improve the model predictions also in the deeper soil layer. Observations frequencies less than a week are required to improve the model simulations compared to the open loop simulation in the present case to best capture dry soil moisture conditions.

The results indicate that there is potential in using (uncertain) surface soil moisture information to improve root zone soil moisture predictions throughout a better parameterization of the physical model. However, the conclusions are limited to the data set used in the present investigation. In case that the soil is layered and not as homogeneous as in case of the present test site, the integration of surface soil moisture information might fail to improve the model predictions. Only minor dependency on the temporal sampling was observed using PTF's. However it was found that the prediction of deeper soil water content benefits from a higher sampling rate of the observations. Using observations with frequencies below one week show improved model skills.

As the FAO soil texture information is available at global scale, a priori information on soil properties might be available from that data set. However, there might be considerable differences between the FAO information and the local soil texture due to the rather coarse scale of that map. It is therefore expected that much worse performance of the inversion algorithm can be expected in case of observation errors $>4$ vol.\% on the one hand side, but that the relative performance, compared to an open loop simulation, might also increase for higher observation uncertainties.
HESSD

$5,95-145,2008$

\section{Soil parameter} inversion - potential and limits

A. Loew and W. Mauser

Title Page

Abstract Introduction

Conclusions

Tables References Figures

14 $\rightarrow \mathbf{I}$

4

Back

Close

Full Screen / Esc

Printer-friendly Version

Interactive Discussion 
The meteorological forcing data which was used for the model simulations was based on local measurements and can therefore be considered as a reliable input for the model simulations. However Loew (2008) ${ }^{1}$ has shown that considerable differences in the model simulations are observed when meteorological data is taken from a station $520 \mathrm{~km}$ apart from the test site which might complicate the inversion of soil characteristics from the surface soil moisture observations. A simultaneous compensation for uncertainties in model forcings as well as in the model parameterisation would then be required. The use of sequential data assimilation techniques as e.g. the Ensemble Kalman Filter (Evensen, 2003) with augmented state vectors might be used in that 10 context together with frequent observations. Forthcoming satellite missions as the SENTINEL-1 mission will allow for that frequent coverage at high spatial resolutions.

Acknowledgements. The work has been supported by the European Space Agency (ESA) under contract 19569/06/NL. Field data was collected within the scope of the AGRISAR 2006 campaign funded by ESA which is gratefully acknowledged.

\section{References}

Attema, E.: GMES Sentinel-1 Mission Requirements Document, Tech. rep., ESA publication, Issue1.4, ES-RS-ESA-SY-0007, 2005. 99

Baldocchi, D., Hicks, B., and P., C.: A canopy stomatal resistance model for gaseous depositions to vegetated surfaces., Atm. Environ. 1987, 21(1), 91-101, 1987. 106

Batjes, N.: Development of a world data set of soil water retention properties using pedotransfer rules, Geoderma, 71(1-2), 31-52, 1996. 98

Beven, K. and Binley, A.: The future of distributed models: model calibration and uncertainty prediction, Hydrol. Processes, 6, 279-298, 1992. 98

Beven, K. and Freer, J.: Equifinality, data assimilation, and uncertainty estimation in mechanistic modelling of complex environmental systems, J. Hydrol., 249, 11-29, 2001. 98

Brooks, R. and Corey, A.: Hydraulic properties of porous media, Tech. rep., Hydrology paper 3. Colorado State University, Fort Collins, Colorado, 1964. 102, 106

de Lannoy, G. J. M., Houser, P. R., Pauwels, V. R. N., and Verhoest, N. E. C.: State and bias

\section{HESSD}

$5,95-145,2008$

\section{Soil parameter} inversion - potential and limits

A. Loew and W. Mauser

Title Page

Abstract

Introduction

Conclusions

Tables

References

Figures

14

$\rightarrow 1$

4

Back

Close

Full Screen / Esc

Printer-friendly Version

Interactive Discussion 
estimation for soil moisture profiles by an ensemble Kalman filter: Effect of assimilation depth and frequency, Water Resour. Res., 43, 1-15, 2006. 98

Cosby, B. J., Hornberger, G. M., Clapp, R. B., and Ginn, T.R.: A statistical exploration of the relationships of soil moisture characteristics to the physical properties of soils, Water Resour. Res., 20, 682-690, 1984. 126

Duan, Q., Soorooshian, S., and Gupta, V.: Effective and efficient global optimisation for conceptual rainfall-runoff models, Water Resour. Res., 28(4), 1015-1031., 1992. 97

Dubois, P., van Zyl, J. J., and Engman, T.: Measuring soil moisture with imaging radars, IEEE Trans. Geosc. Rem. Sens, 33, 915-926, 1995. 98

10 Eagleson, P.: Climate, soil, and vegetation, simplified model of soil-moisture movement in liquid-phase, Water Resour. Res., 14(5), 722-730, 1978. 106

Enthekabi, D., Nakamura, H., and Njoku, E.: Solving the inverse problem for soil moisture and temperature profiles by sequential assimilation of multifrequency remotely sensed obersvations, IEEE Trans. Geosc. Rem. Sens, 32(2), 438-448, 1994. 99

15 Evensen, G.: The Ensemble Kalman Filter: theoretical formulation and practical implementation, Ocean Dynamics, 53, 343-367, doi:10.1007/s10236-003-0036-9, 2003. 121

FAO: The digitised soil map of the world, World Soil Resources Report, 67(1), 1991. 98, 109, 110

Gupta, H. V., Bastidas, L. A., Sorooshian, S., Shuttleworth, W. J., and Yang, Z. L.: Parameter estimation of a land surface scheme using multi-criteria methods, J. Geophys. Res., 104, 19491-19504, 1999. 97

Hajnsek, I., Bianchi, R., Davidson, M., DUrso, G., Gomez-Sanchez, J., Hausold, A., Horn, R., Howse, J., Loew, A., Lopez-Sanchez, J., Ludwig, R., Martinez-Lozano, J., Mattia, F., Miguel, E., Moreno, J., Pauwels, V., Ruhtz, T., Schmullius, C., Skriver, H., Sobrino, J., Timmermans, W., Wloczyk, C., and Wooding, M.: AgriSAR 2006 Airborne SAR and Optics Campaigns for an improved monitoring of agricultural processes and practices, European Geoscience Union (EGU), General Assembly, 15-20 April 2007, Vienna, Austria, 2007. 100, 107

Hogue, T. S., Bastidas, L., Gupta, H., Sorooshian, S., Mitchell, K., and Emmerich, W.: Evaluation and transferability of the Noah land surface model in semiarid environments, J. Hydrol.,

$30 \quad 6,68-84,2005.97$

Lee, D.-H.: Comparing the inverse parameter estimation approach with pedo-transfer function method for estimating soil hydraulic conductivity, Geosci. J., 9(3), 269-276, 2005. 98

Liu, Y., Gupta, H. V., Sorooshian, S., Bastidas, L. A., and Shuttleworth, W. J.: Constraining land

\section{HESSD}

5, 95-145, 2008

\section{Soil parameter} inversion - potential and limits

A. Loew and W. Mauser

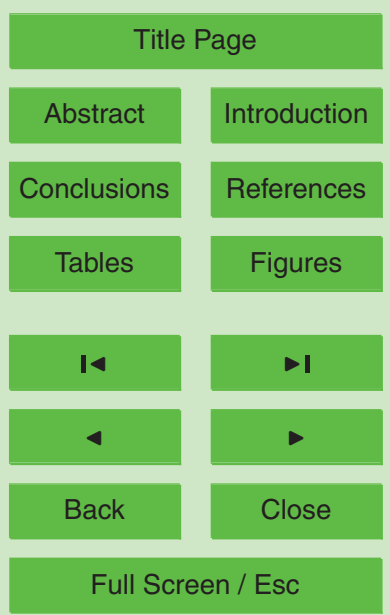

Printer-friendly Version

Interactive Discussion 
surface and atmospheric parameters of a locally coupled model using observational data, J. Hydrometeorol., 6, 156-172, 2005. 97

Loew, A.: Impact of surface heterogeneity on surface soil moisture retrievals from passive microwave data at the regional scale: the Upper Danube case, Rem. Sens. Env., 112, 231$5 \quad 248$, doi:10.1016/j.rse.2007.04.009, 2008. 98, 110

Loew, A., Ludwig, R., and Mauser, W.: Derivation of surface soil moisture from ENVISAT ASAR WideSwath and Image mode data in agricultural areas, IEEE Trans. Geosc. Rem. Sens, 44(4), 889-899, 2006. 98, 99

Ludwig, R. and Mauser, W.: Modelling catchment hydrology within a GIS-based SVAT-model framework, Hydrol. Earth Syst. Sci., 4(2), 239-249, 2000. 107

Madsen, H., Wilson, G., and Ammentorp, H.: Comparison of different automated strategies for calibration of rainfallrunoff models, J. Hydrol., 261(1-4), 48-59, 2002. 97

Mauser, W. and Schaedlich, S.: Modelling the spatial distribution of evapotranspiration using remote sensing data and PROMET, J. Hydrol., 213, 250-267, 1998. 106, 107

Mertens, J., Stenger, R., and Barkle, G. F.: Multiobjective Inverse Modeling for Soil Parameter Estimation and Model Verification, Vadose Zone Journal, 5, 917-933, 2006. 97

Monteith, J.: Evaporation and the environment, Proc. Symposium of the society of exploratory biology, 19, 205-234, 1965. 106

Nash, J. and Sutcliffe, J.: River flow forecasting through conceptual models part I - A discussion 20 of principles, J. Hydrol., 10(3), 282-290, 1970. 105

Nelder, J. and Mead, R.: A simplex method for function minimization, The Computer Journal, 7, 308-313, 1965. 105

Norman, J., Barfield, B., and Gerber, J.: Modification of the Aerial Environment of Plants, chap, Modelling the complete crop canopy, Am. Soc. Agr. Eng., 249-277, 1979. 106

Owe, M., de Jeu, R., and Holmes, T.: Multi-Sensor Historical Climatology of Satellite-Derived Global Land Surface Moisture, J. Geophys. Res., in press, 2008. 96

Pauwels, V., Timmermans, W., and Loew, A.: Study of the water and energy budget during AGRISAR 2006, J. Hydrol., in press, 2008. 107, 108, 119

Pulliainen, J., Karna, J.-P., and Hallikainen, M.: Development of geophysical retrieval algorithms for the MIMR, IEEE Trans. Geosc. Rem. Sens, 31(1), 268-277, 1993. 104

Rawls, W. and Brakensiek, D.: Prediction of soil water retention properties for hydrologic modelling, Watershed Management in the Eighties, Proc. Symposium of Irrig. Drainage Div. ASCE, Denver, CO., 30 April-1 May 1985, 293-299, 1985. 102, 118, 126

HESSD

5, 95-145, 2008

Soil parameter inversion - potential and limits

A. Loew and W. Mauser

Title Page

Abstract

Introduction

Conclusions

References

Tables

Figures

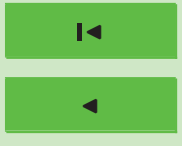

$\rightarrow$

Back

Close

Full Screen / Esc

Printer-friendly Version

Interactive Discussion 
Rawls, W., Gish, T., and Brakensiek, D.: Estimating soil water retention from soil physical properties and characteristics, Adv. Soil Sci., 16, 213-234, 1991. 98

Reichle, R., Entekhabi, D., and McLaughlin, D.: Variational Data assimilation of microwave radiobrightness observations for land surface hydrology applications, IEEE Trans. Geosc. Rem. Sens, 39(8), 1708-1718, 2001. 99

Reichle, R. H. and Koster, R.: Global assimilation of satellite surface soil moisture retrievals into the NASA catchment land surface model, Geophys. Res. Lett., 32, L02404, doi:10.1029/ 2004GL021700, 2005. 99

Richards, L.: Capillary conduction of liquids through porous mediums, Physics, 1, 318-333, 1931. 101

Robock, A., Vinnikov, K. Y., Srinivasan, G., Entin, J. K., Hollinger, S. E., Speranskaya, N. A., Liu, S., and Namkha, A.: The Global Soil Moisture Data Bank, B. Am. Meteor. Soc., 1281-1299, 2000. 98

Santanello, J. A., Peters-Lidard, C. D., Garcia, M. E., Mocko, D. M., Tischler, M. A., Moran, S., and Thoma, D.: Using remotely-sensed estimates of soil moisture to infer soil texture and hydraulic properties across a semi-arid watershed, Rem. Sens. Env., 110, 79-97, 2007. 97, 98

Saxton, K. E., Rawls, W. J., Romberger, J. S., and Papendick, R. I.: Estimating generalized soil-water characteristics from texture, Soil Sci. Soc. Am. J., 50, 1031-1036, 1986. 126

Scheinost, A. C., Sinowski, W., and Auerswald, K.: Regionalization of soil water retention curves in a highly variable soilscape, I.: Developing a new pedotransfer function, Geoderma, 78, 129-143, 1997. 126

Strasser, U. and Mauser, W.: Modelling the spatial and temporal variations of the water balance for the Weser catchment 1965-1994, J. Hydrol., 254(1-4), 199-214, 2001. 106

Thyer, M., Kuczera, G., and Bates, B.: Probabilistic optimisation for conceptual rainfallrunoff models: a comparison of the shuffled complex evolution and simulated annealing algorithms, Water Resour. Res., 35(3), 767-773, 1999. 97

Vrugt, J., Gupta, H., Bastidas, L., Bouten, W., and Soorooshian, S.: Effective and efficient algorithm for multiobjective optimiztion of hydrological models, Water Resour. Res., 39(8), $30 \quad$ 2003. 97

Vrugt, J., Robinson, B. A., and Vesselinov, V.: Improved inverse modeling for flow and transport in subsurface media: Combined parameter and state estimation, Geophys. Res. Lett., 32, L18408, doi:10.1029/2005GL023940, 2005. 97, 98

\section{HESSD}

5, 95-145, 2008

Soil parameter inversion - potential and limits

A. Loew and W. Mauser

Title Page

Abstract

Introduction

Conclusions

Tables

References

Figures

14

-1

4

Back

Close

Full Screen / Esc

Printer-friendly Version

Interactive Discussion 
Wagner, B., Tarnawski, V., Hennings, V., Mller, U., Wessolek, G., and Plagge, R.: Evaluation of pedo-transfer functions for unsaturated soil hydraulic conductivity using an independatn data set, Geoderma, 102, 275-297, 2001. 102

Wagner, W., Blschl, G., Pampaloni, P., Calvet, J.-C., Bizzarri, B., Wigneron, J.-P., and Kerr, Y.: 5 Operational readiness of microwave remote sensing of soil moisture for hydrologic applications, Nordic Hydrology, 38(1), 1-20, 2007a. 98, 99, 110

Wagner, W., Naeimi, V., Scipal, K., deJeu, R., and Martnez-Fernández, J.: Soil moisture from operational meteorological satellites, Hydrogeol. J., 15, 121-131, 2007b. 99

Walker, J., Willgoose, G., and Kalma, J.: One-dimensional soil moisture profile retrieval by assimilation of near-surface observations: a comparison of retrieval algorithms, Adv. Water Res., 24, 631-650, 2001. 99

Walker, J. P. and Houser, P.: Hydrologic Data Assimilation, chap. Advances in Water Science Methodologies, A.A. Balkema, The Netherlands, 2005. 101

Woesten, J.: Soil Quality for Crop Production and Ecosystem Health. Development in Soil Science, chap. Pedotransfer functions to evaluate soil quality, 221-245, Elsevier, 1997. 98, 103

Woesten, J., Lilly, A., Nemes, A., and LeBas, C.: Development and use of a database of hydraulic properties of European soils, Geoderma, 90, 169-185, 1999. 98, 126

Woesten, J., Pachepsky, Y. A., and Rawls, W.: Pedotransfer functions: bridging the gap between available basic soil data and missing soil hydraulic characteristics, J. Hydrol., 251, 123-150, 2001. 98, 102

Yapo, P., Gupta, H., and Sorooshian, S.: Multi-objective global optimization for hydrologic models, J. Hydrol., 204(1-4), 83-97, 1998. 97

Zadoks, J., Chang, T., and Konzak, C.: A decimal code for the growth stages of cereals, Weed Res., 14(6), 415-421, 1974. 108

\section{HESSD}

5, 95-145, 2008

\section{Soil parameter} inversion - potential and limits

A. Loew and W. Mauser

Title Page

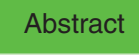

Introduction

Conclusions

References

Tables

Figures

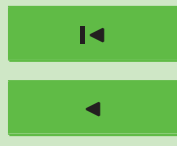

$\rightarrow$

Back

Close

Full Screen / Esc

Printer-friendly Version

Interactive Discussion 


\section{HESSD}

5, 95-145, 2008

Table 1. Overview of used pedotransfer functions.

\begin{tabular}{|c|c|}
\hline$K_{s}$ & $\begin{array}{l}\text { Cosby et al. (1984) } \\
\text { Woesten et al. (1999) } \\
\text { Rawls and Brakensiek (1985) } \\
\text { Saxton et al. (1986) }\end{array}$ \\
\hline$\phi$ & $\begin{array}{l}\text { Scheinost et al. (1997) } \\
\text { Cosby et al. (1984) } \\
\text { Saxton et al. (1986) }\end{array}$ \\
\hline$\theta_{r}$ & $\begin{array}{l}\text { Rawls and Brakensiek (1985) } \\
\text { Scheinost et al. (1997) }\end{array}$ \\
\hline$\lambda$ & Rawls and Brakensiek (1985) \\
\hline$h_{b}$ & Rawls and Brakensiek (1985) \\
\hline
\end{tabular}

\section{Soil parameter inversion - potential and limits}

A. Loew and W. Mauser

Title Page

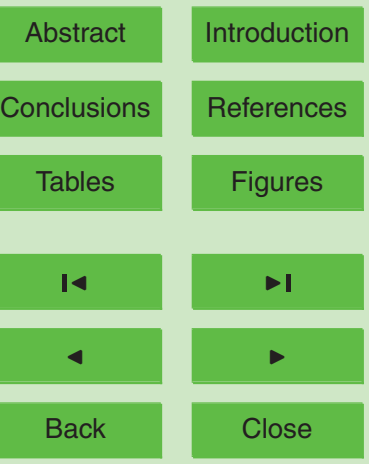

Full Screen / Esc

Printer-friendly Version

Interactive Discussion 


\section{HESSD}

5, 95-145, 2008

\section{Soil parameter inversion - potential and limits}

A. Loew and W. Mauser

Table 2. RMS error, model efficiency and coefficient of determination between measured surface soil moisture and PROMET simulations.

\begin{tabular}{lllll}
\hline & \multicolumn{2}{c}{$r m s[v o l . \%]$} & \multicolumn{2}{c}{$E[-]$} \\
Model parameterization & $5 \mathrm{~cm}$ & $25 \mathrm{~cm}$ & $5 \mathrm{~cm}$ & $25 \mathrm{~cm}$ \\
\hline FAO & 3.05 & 2.39 & 0.71 & 0.83 \\
Laboratory & 3.05 & 2.60 & 0.71 & 0.80 \\
Cosby (1984) & 3.12 & $\mathbf{2 . 3 8}$ & 0.70 & $\mathbf{0 . 8 3}$ \\
Saxton (1986) & $\mathbf{2 . 9 8}$ & 3.37 & $\mathbf{0 . 7 3}$ & 0.66 \\
Woesten (1999) & 3.12 & $\mathbf{2 . 3 8}$ & 0.70 & $\mathbf{0 . 8 3}$ \\
\hline
\end{tabular}

Title Page

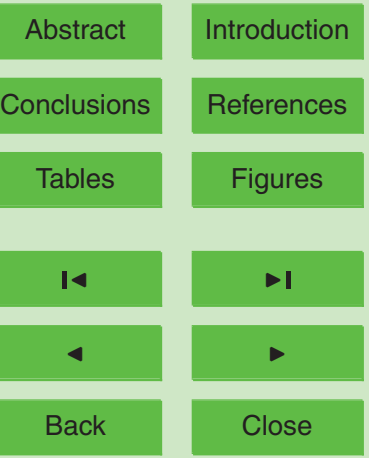

Full Screen / Esc

Printer-friendly Version

Interactive Discussion 


\section{HESSD}

5, 95-145, 2008

Table 3. Summary of parameterisations used for simulation runs.

\begin{tabular}{|c|c|c|c|c|c|c|}
\hline & \multirow[b]{2}{*}{ unit } & \multicolumn{5}{|c|}{ Scenario } \\
\hline & & A & B1 & B2 & $\mathrm{C} 1$ & $\mathrm{C} 2$ \\
\hline Observation error $v$ & $\mathrm{~cm}^{3} / \mathrm{cm}^{3}$ & [1 $124 \quad 46]$ & {$\left[\begin{array}{lllllllllllllll}1 & 2 & 4 & 6\end{array}\right]$} & {$\left[\begin{array}{llll}1 & 2 & 4 & 6\end{array}\right]$} & {$\left[\begin{array}{lllllllllllllllll}1 & 2 & 4 & 6\end{array}\right]$} & {$\left[\begin{array}{llllllllllll}1 & 2 & 4 & 6\end{array}\right]$} \\
\hline Parameter constraint & & - & No & No & Yes $\left(\sigma_{p}=10.\right)$ & Yes $\left(\sigma_{p}=25.\right)$ \\
\hline $\begin{array}{l}\text { Free parameters } \\
\text { Cost function } J\end{array}$ & & $\begin{array}{c}\lambda, h_{b}, \phi, K_{s} \\
\text { (12) }\end{array}$ & $\begin{array}{l}\text { s, C } \\
(12)\end{array}$ & $\begin{array}{l}\text { s, c } \\
(12)\end{array}$ & $\begin{array}{l}\text { S, C } \\
(11)\end{array}$ & $\begin{array}{l}\mathrm{S}, \mathrm{C} \\
(11)\end{array}$ \\
\hline$s_{0}, c_{0}$ & {$[\%]$} & - & FAO & $30 / 30$ & FAO & $30 / 30$ \\
\hline \multicolumn{7}{|c|}{ Parameter uncertainties: mean (standard deviation) } \\
\hline$\lambda$ & - & - & - & - & $0.34(0.09)$ & $0.19(0.1)$ \\
\hline$K_{s}$ & - & - & - & - & $0.0036(0.00034)$ & $0.00016(0.0003)$ \\
\hline$\theta_{r}$ & - & - & - & - & $9.2(3.0)$ & $12.2(7.0)$ \\
\hline$\phi$ & - & - & - & - & $0.38(0.006)$ & $0.41(0.004)$ \\
\hline$h_{b}$ & - & - & - & - & $50.88(23.6)$ & $177.3(123.2)$ \\
\hline
\end{tabular}

A. Loew and W. Mauser

Soil parameter inversion - potential and limits

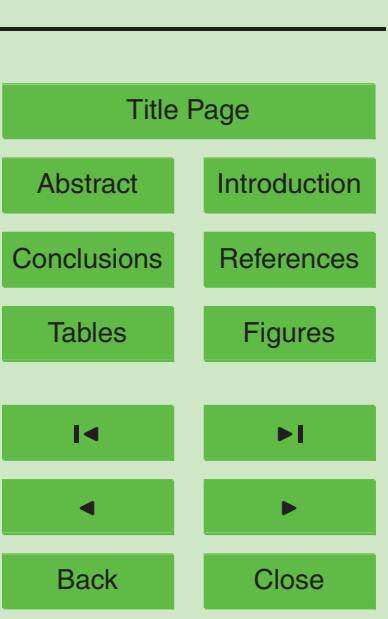

Full Screen / Esc

Printer-friendly Version

Interactive Discussion 


\section{HESSD}

5, 95-145, 2008

\section{Soil parameter inversion - potential and limits}

A. Loew and W. Mauser

Table 4. Mean and standard deviation of soil texture residues.

\begin{tabular}{lcr}
\hline Scenario & Clay (\%) & Sand (\%) \\
\hline B1 & $0.54(2.64)$ & $0.75(5.80)$ \\
B2 & $2.01(7.08)$ & $-14.22(8.04)$ \\
C1 & $\mathbf{0 . 4 3}(2.39)$ & $\mathbf{0 . 3 8}(2.94)$ \\
C2 & $3.06(7.75)$ & $-13.55(7.61)$ \\
\hline
\end{tabular}

Title Page

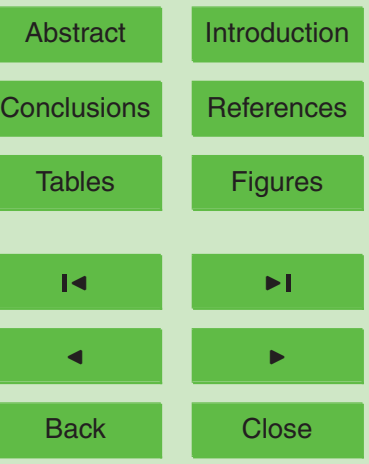

Full Screen / Esc

Printer-friendly Version

Interactive Discussion 


\section{HESSD}

5, 95-145, 2008

Table 5. Soil hydraulic parameters for FAO and laboratory data compared against retrieval results and literature data.

\begin{tabular}{|c|c|c|c|c|}
\hline Parameter & Sandy loam & FAO & Laboratory & Inversion \\
\hline$h_{b}$ & $\begin{array}{r}14.66 \\
(3.45-62.24)\end{array}$ & 14.69 & 10.96 & $\begin{array}{r}35.04 \\
\pm 5.49\end{array}$ \\
\hline$\lambda$ & $\begin{array}{r}0.378 \\
(0.140-0.616)\end{array}$ & 0.34 & 0.33 & $\begin{array}{r}0.372 \\
\pm 0.02\end{array}$ \\
\hline$\theta_{r}$ & $\begin{array}{r}4.1 \\
(2.4-10.6)\end{array}$ & 7.8 & 8.2 & $\begin{array}{r}5.46 \\
\pm 1.3\end{array}$ \\
\hline$K_{s}$ & $2.0-5.0$ & 1.97 & 1.24 & $\begin{array}{r}6.96 \\
\pm 6.80\end{array}$ \\
\hline$\phi$ & $\begin{array}{r}45.3 \\
(35.1-55.5)\end{array}$ & 42.6 & 41.7 & $\begin{array}{r}39.7 \\
\pm 4.4\end{array}$ \\
\hline
\end{tabular}

\section{Soil parameter} inversion - potential and limits

A. Loew and W. Mauser

Title Page

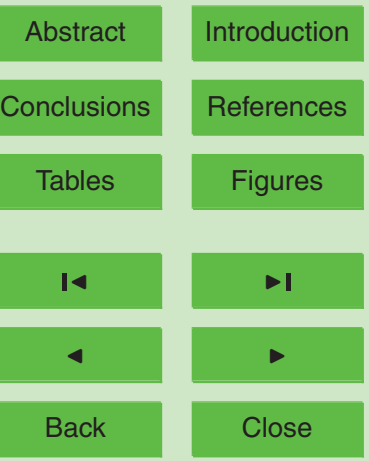

Full Screen / Esc

Printer-friendly Version

Interactive Discussion 


\section{HESSD}

5, 95-145, 2008

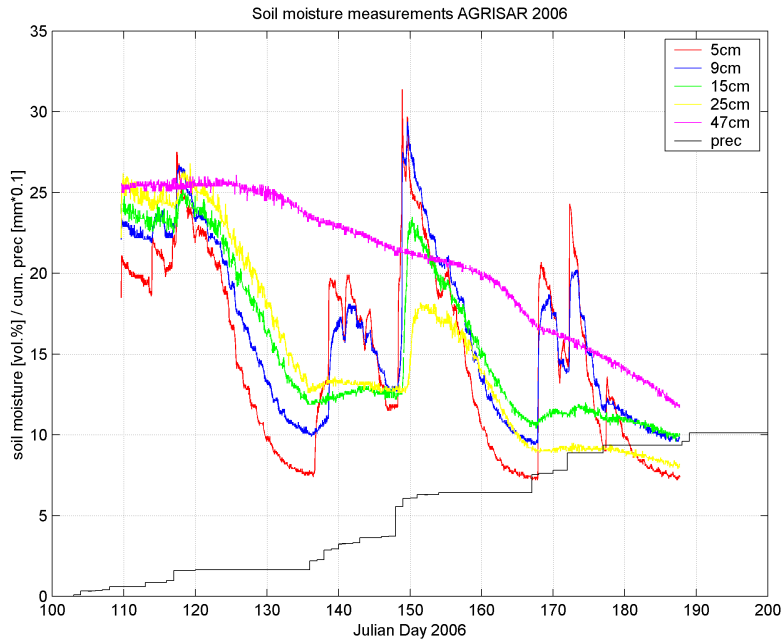

\section{Soil parameter inversion - potential and limits}

A. Loew and W. Mauser

Title Page

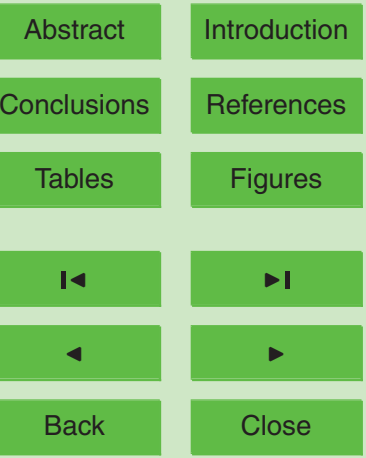

Full Screen / Esc

Printer-friendly Version

Interactive Discussion 


\section{HESSD}

5, 95-145, 2008

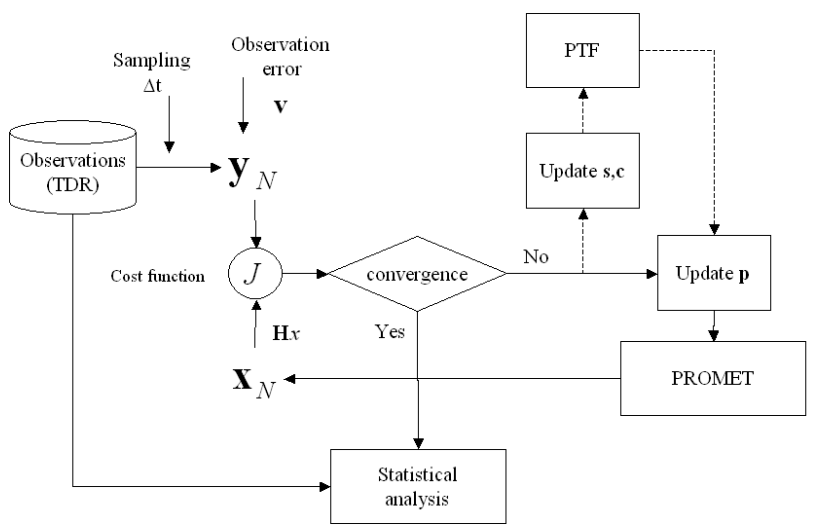

\section{Soil parameter inversion - potential and limits}

A. Loew and W. Mauser

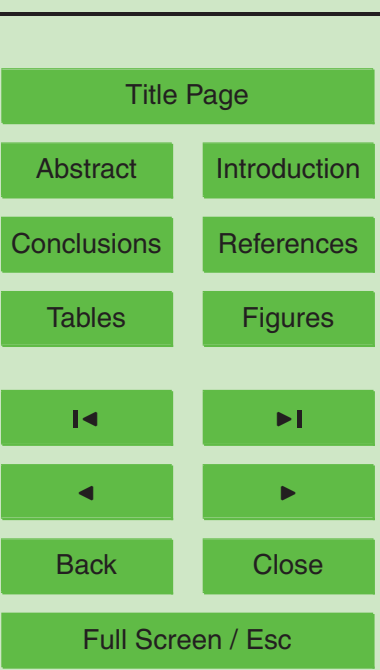

Printer-friendly Version

Fig. 2. Inverse modelling of soil characteristics using surface soil moisture observations and PROMET model simulations with (dotted line) and without (solid line) using PTF's.

Interactive Discussion 


\section{HESSD}

5, 95-145, 2008

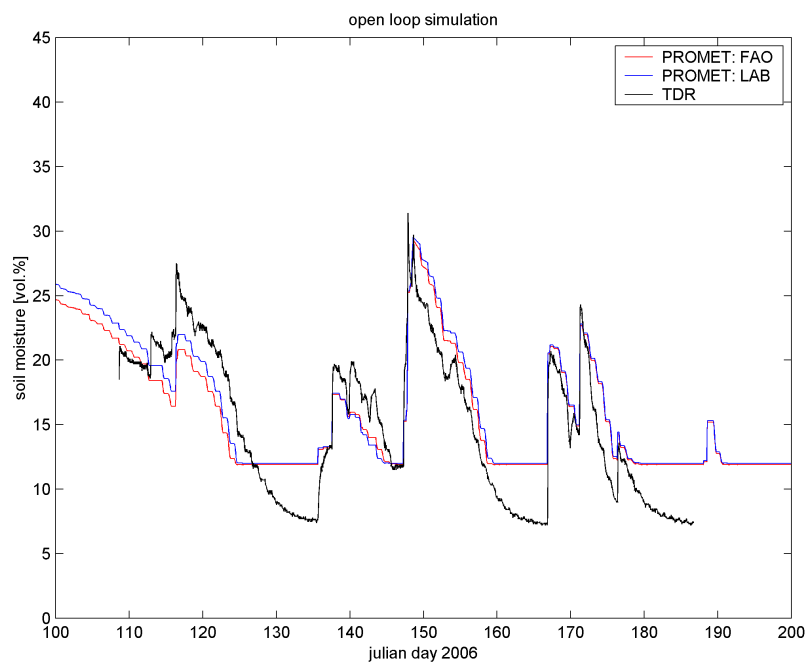

\section{Soil parameter} inversion - potential and limits

A. Loew and W. Mauser

Title Page

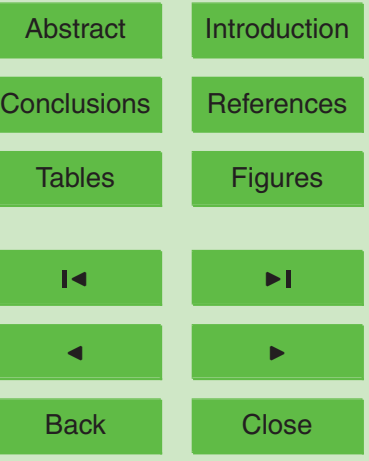

Full Screen / Esc using $\mathrm{FAO}$ and laboratory soil texture information.

Printer-friendly Version

Interactive Discussion 


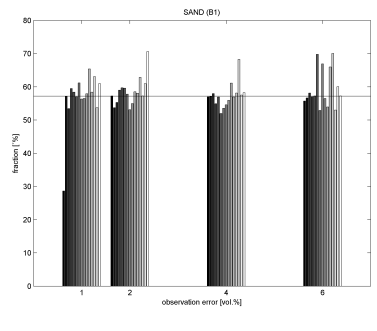

HESSD

5, 95-145, 2008

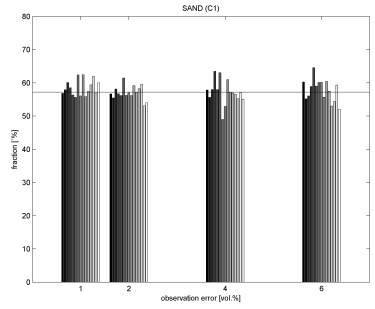
inversion - potential and limits

A. Loew and W. Mauser

Title Page

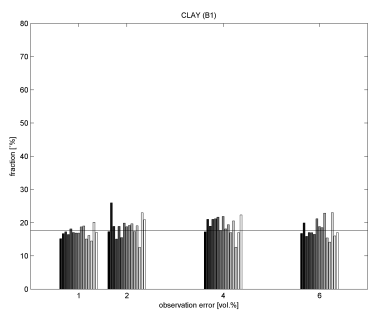

Introduction
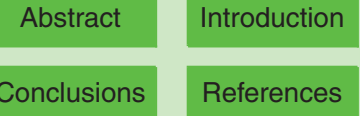

Conclusions

Tables

Figures

I
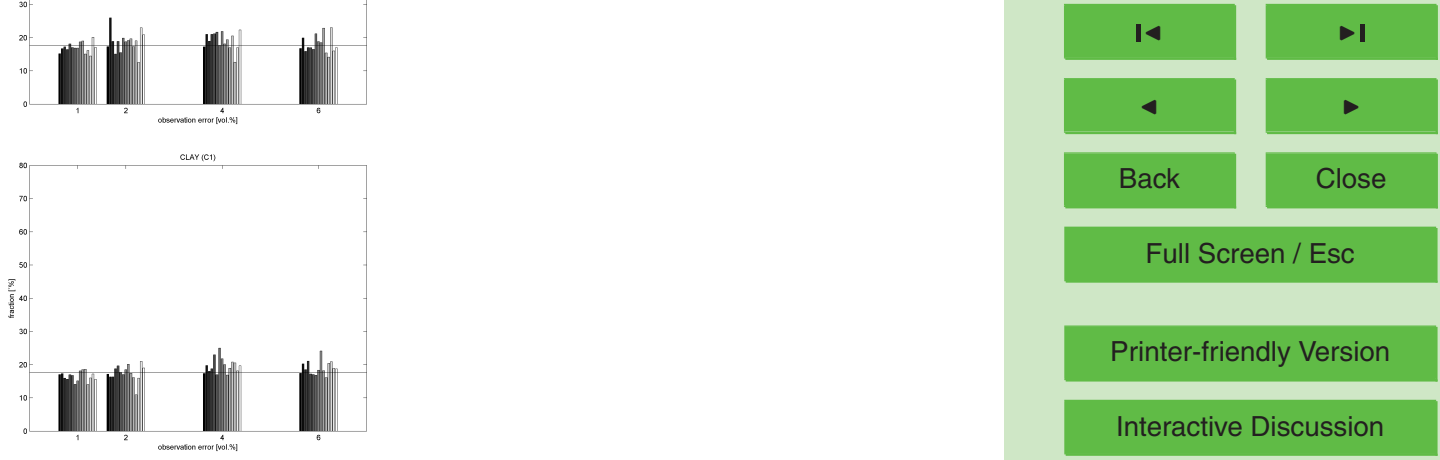

Back

Close

Full Screen / Esc

Printer-friendly Version

Interactive Discussion

Fig. 4. Soil texture retrieval results for the different scenarios. 


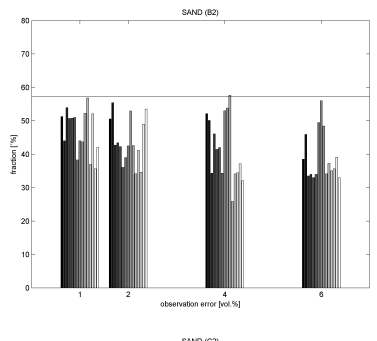

HESSD

5, 95-145, 2008

\section{Soil parameter} inversion - potential and limits

A. Loew and W. Mauser

Title Page

Abstract

Introduction

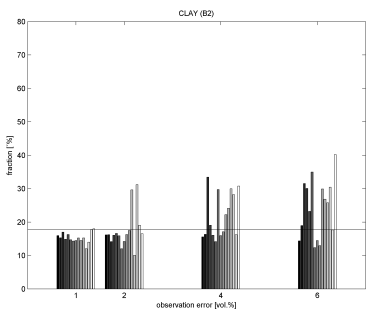

Conclusions

References

Tables

Figures

14
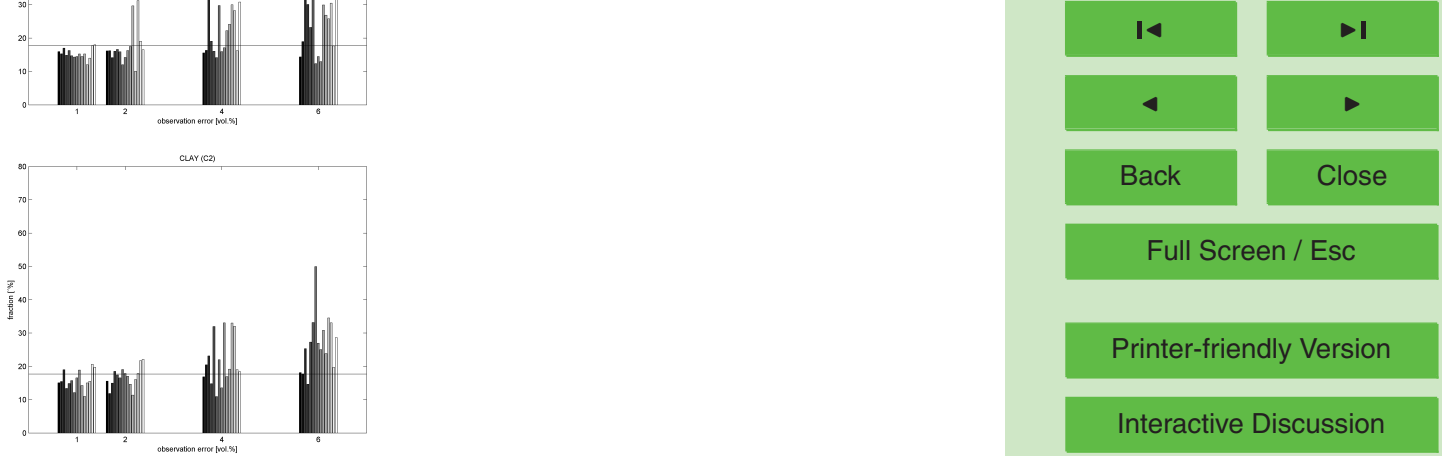

Back

Close

Full Screen / Esc

Printer-friendly Version

Interactive Discussion

EGU 


\section{HESSD}

5, 95-145, 2008

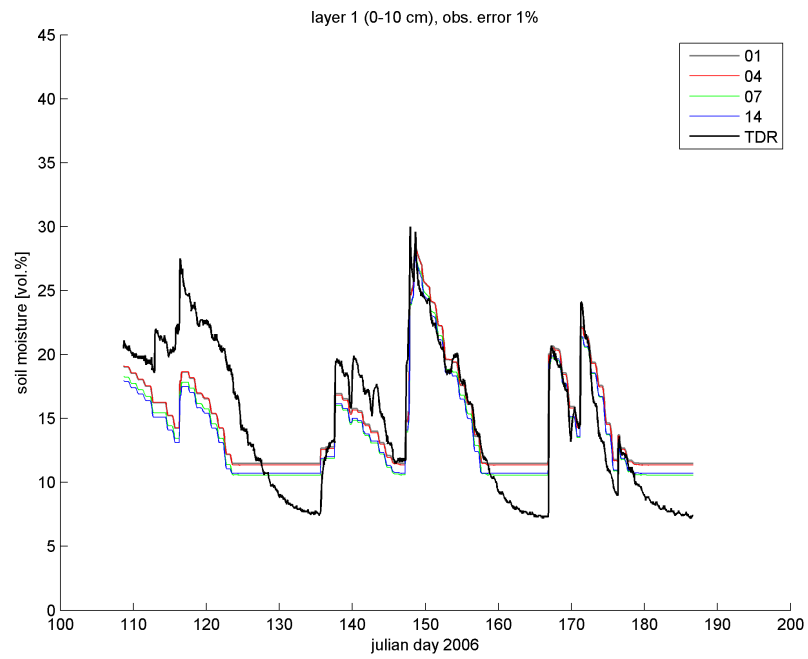

\section{Soil parameter} inversion - potential and limits

A. Loew and W. Mauser

Title Page

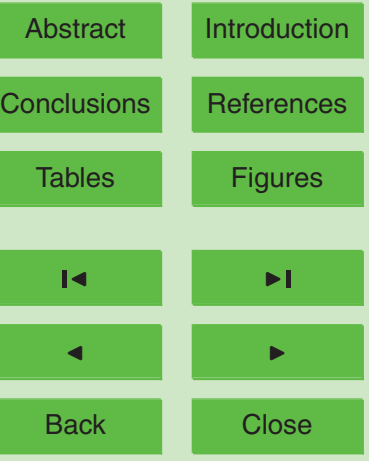

Full Screen / Esc from different observation frequencies ( $\mathrm{C} 1$ scenario, $\mathrm{v}=1 \%$ ).

Printer-friendly Version

Interactive Discussion 


\section{HESSD}

5, 95-145, 2008

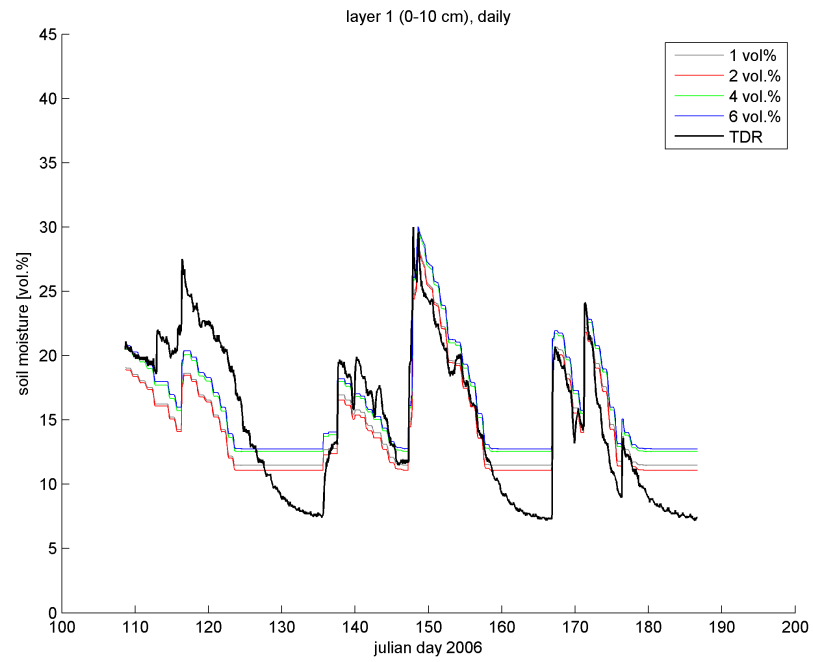

\section{Soil parameter} inversion - potential and limits

A. Loew and W. Mauser

Title Page

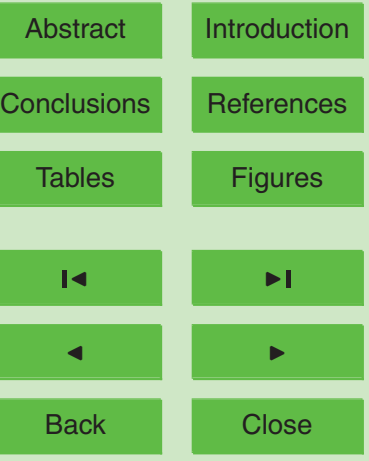

Full Screen / Esc with different observation accuracies ( $\mathrm{C} 1$ scenario, $\Delta t=1$ day).

Printer-friendly Version

Interactive Discussion 

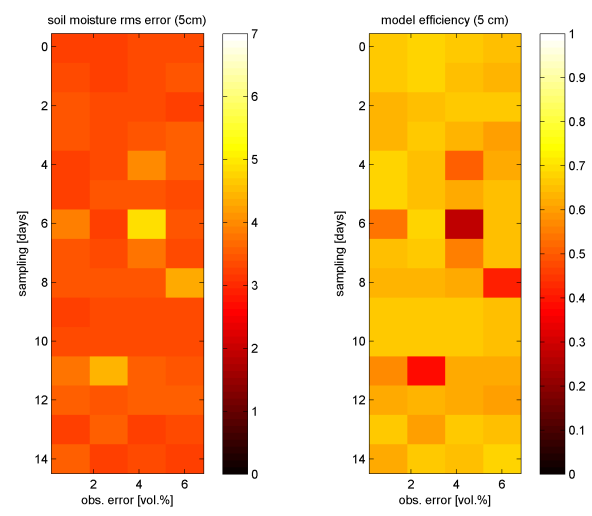

\section{HESSD}

5, 95-145, 2008
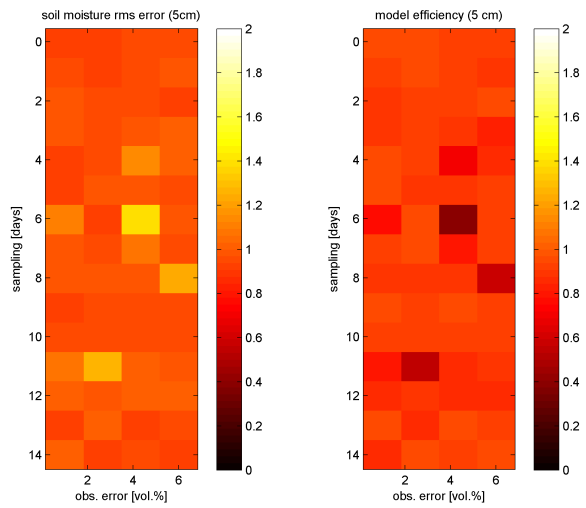

Title Page

Abstract

Conclusions

Tables

14

4

Back
Introduction

References

Figures

$\rightarrow 1$

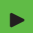

Close

Full Screen / Esc

Fig. 7. Comparison of normalized (bottom) and un-normalized (top) values for rms error and model efficiency for $\mathrm{C} 1$ scenario.

Printer-friendly Version

Interactive Discussion 

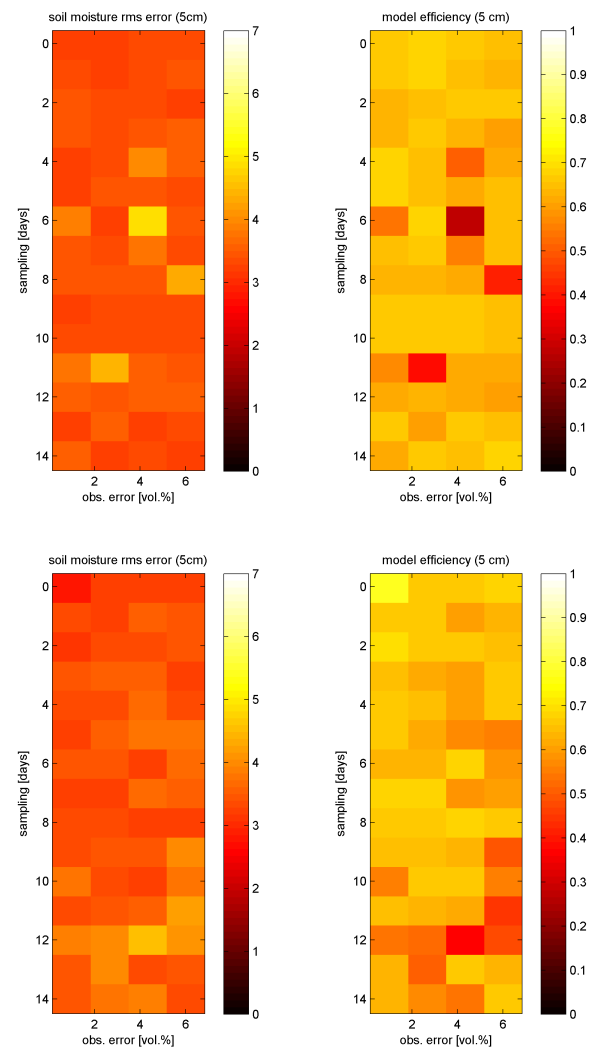

Fig. 8. RMS error and model efficiency for the constrained (C1, top) and unconstrained (B1, bottom) case.

\section{HESSD}

5, 95-145, 2008

\section{Soil parameter inversion - potential and limits}

A. Loew and W. Mauser

Title Page

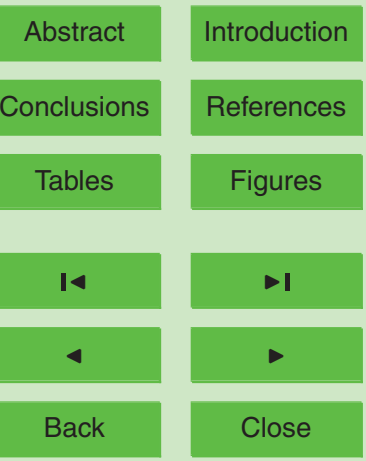

Full Screen / Esc

Printer-friendly Version

Interactive Discussion 


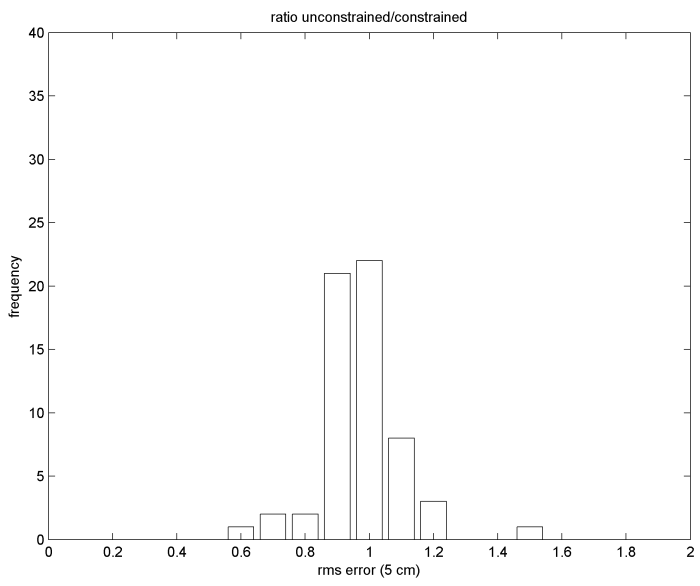

HESSD

$5,95-145,2008$

\section{Soil parameter inversion - potential and limits}

A. Loew and W. Mauser

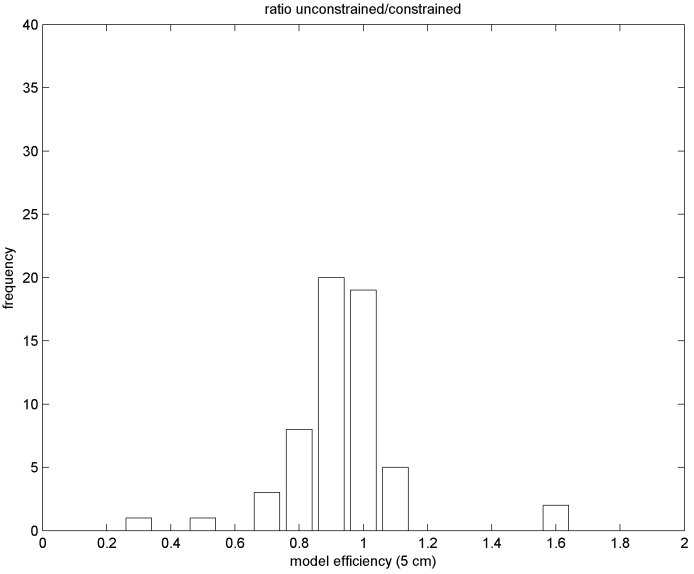

Title Page

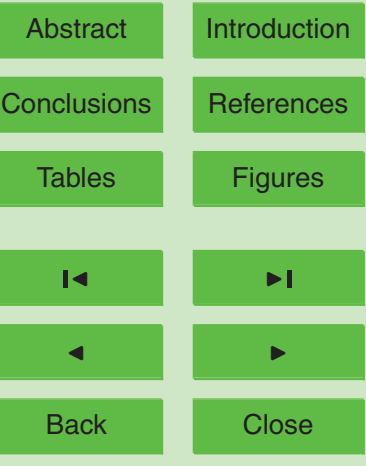

Full Screen / Esc

Printer-friendly Version

Interactive Discussion

Fig. 9. Frequency distribution of ratio between unconstrained (B1) and constrained (C1) simulation results from surface soil moisture rms error and model efficiency. 

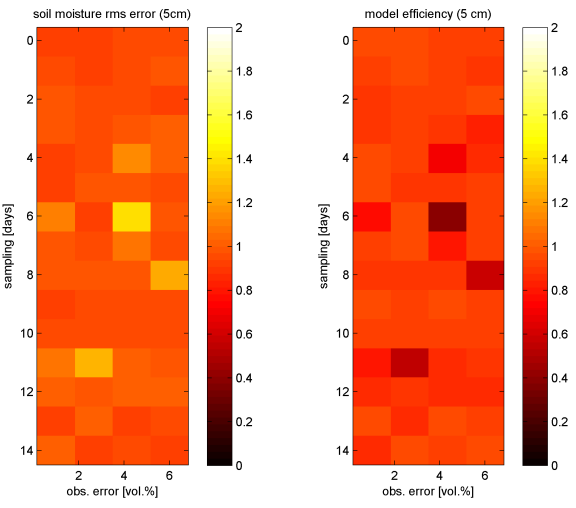

\section{HESSD}

5, 95-145, 2008

\section{Soil parameter inversion - potential and limits}

A. Loew and W. Mauser
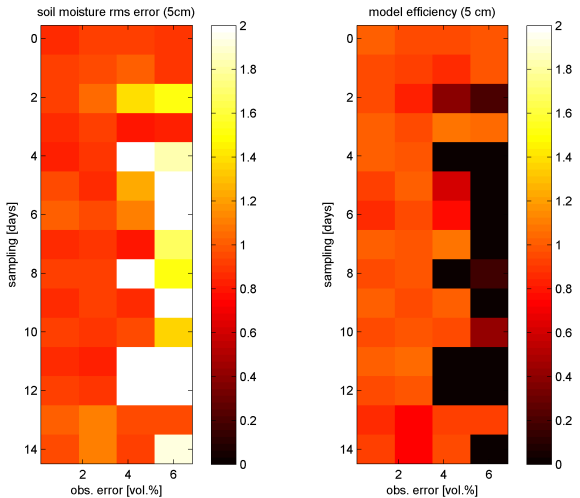

Title Page

Abstract

Conclusions

Tables

I

4

Back
Introduction

References

Figures

$>$ I

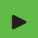

Close

\section{Full Screen / Esc}

Printer-friendly Version

Fig. 10. Normalized rms error and model efficiency with (top, C1) and without (bottom, C2) a priori information on soil texture.

Interactive Discussion 


\section{HESSD}

5, 95-145, 2008

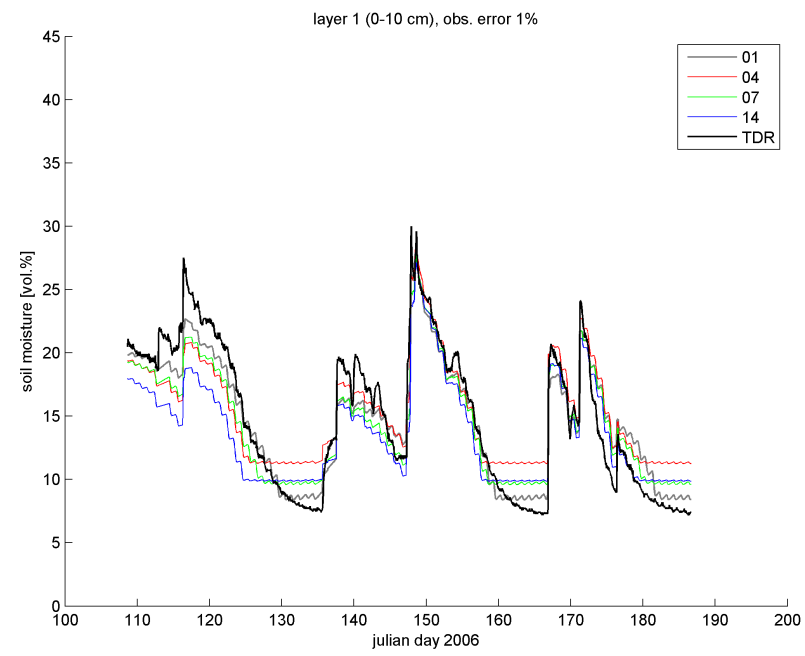

\section{Soil parameter} inversion - potential and limits

A. Loew and W. Mauser

Title Page

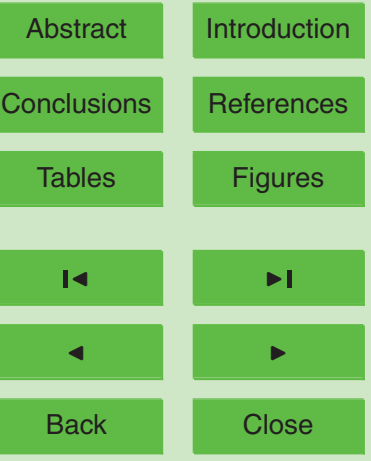

Full Screen / Esc A) for different sampling intervals.

Printer-friendly Version

Interactive Discussion 

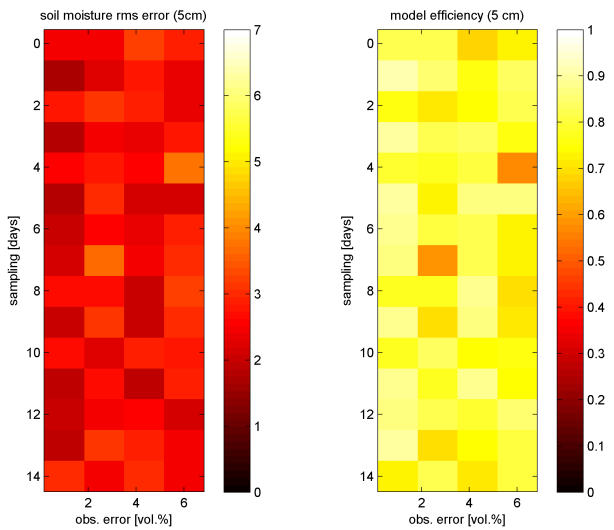

\section{HESSD}

5, 95-145, 2008

\section{Soil parameter inversion - potential and limits}

A. Loew and W. Mauser
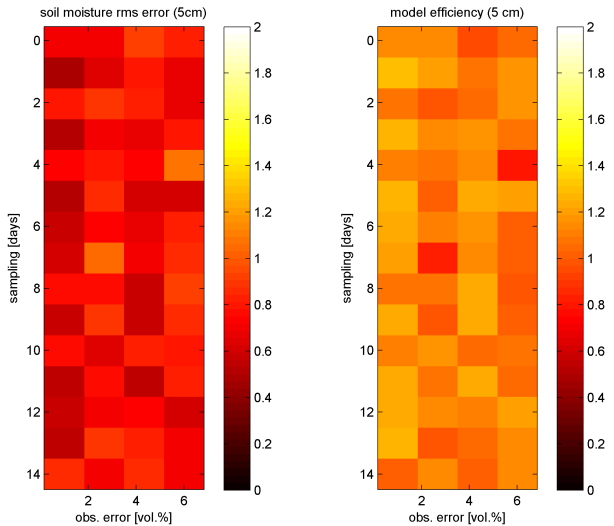

Title Page

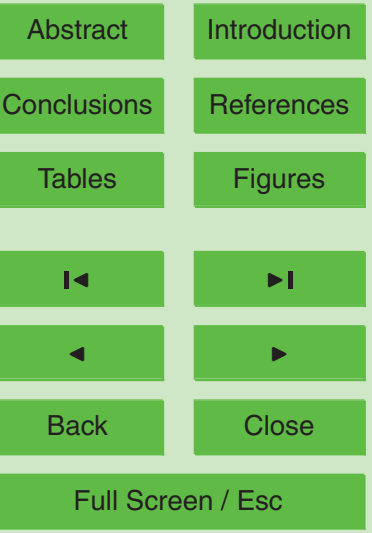

Fig. 12. Soil moisture rms error and model efficiency for scenario A: absolute values (top) and normalized by open loop simulation (bottom). 


\section{HESSD}

5, 95-145, 2008

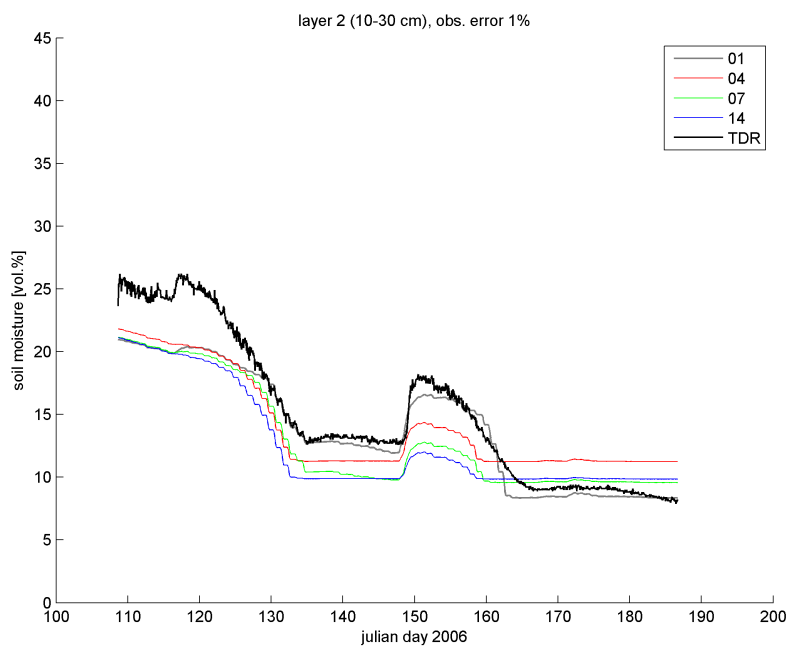

\section{Soil parameter inversion - potential and limits}

A. Loew and W. Mauser

Title Page

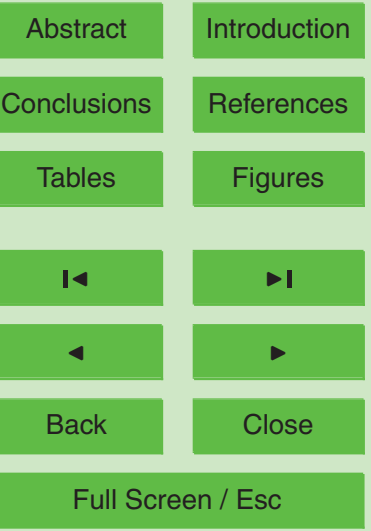

Printer-friendly Version

Interactive Discussion 


\section{HESSD}

5, 95-145, 2008
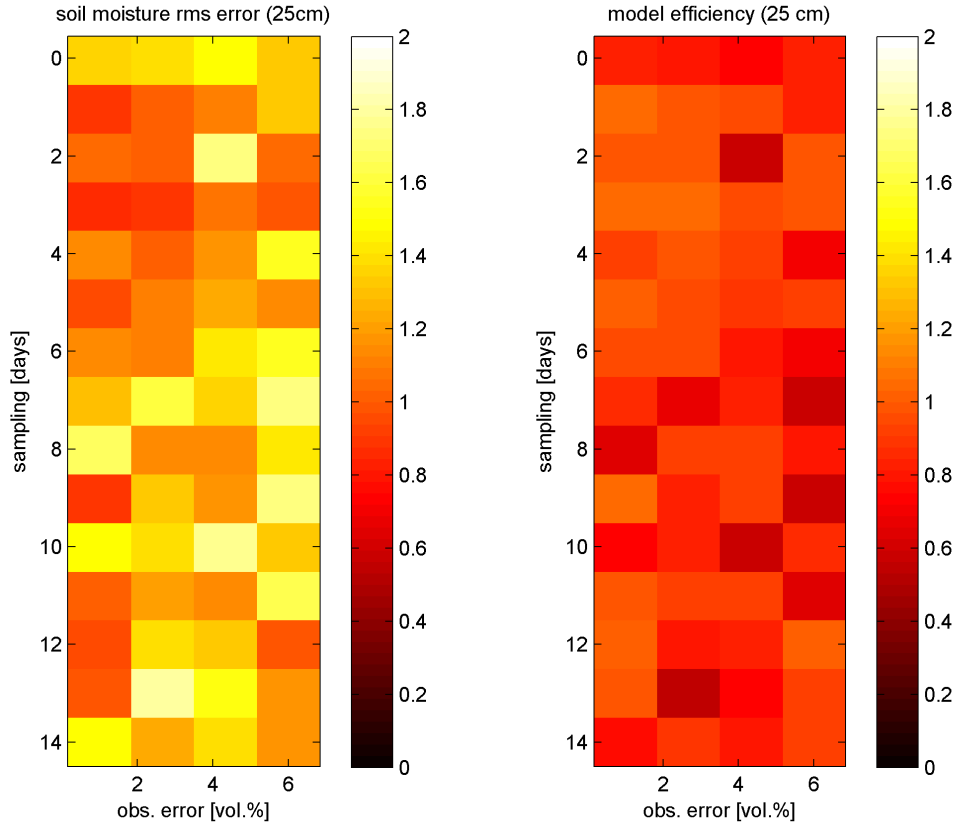

Soil parameter inversion - potential and limits

A. Loew and W. Mauser

Title Page

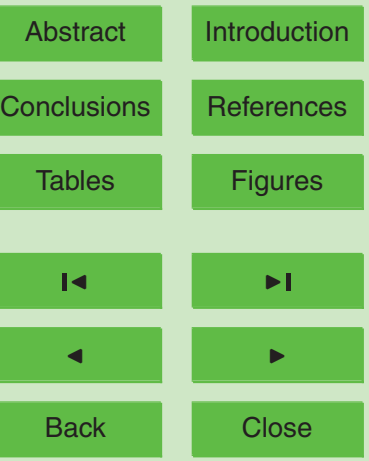

Full Screen / Esc

Fig. 14. Normalized rms error and model efficiency of the deeper soil layer for different temporal sampling and observation errors (scenario A).

Printer-friendly Version

Interactive Discussion 